\title{
Acquisition, processing and analysis of densely sampled P- and S-wave OBS-data on the mid-Norwegian Margin, NE Atlantic
}

\author{
Rolf Mjelde ${ }^{1 *}$, Tommy Timenes ${ }^{2}$, Hideki Shimamura ${ }^{3}$, Toshihiko Kanazawa ${ }^{4}$, Hajime Shiobara ${ }^{3 *}$, \\ Shuichi Kodaira ${ }^{3 * *}$, and Ayako Nakanishi ${ }^{3 * *}$ \\ ${ }^{1}$ Institute of Solid Earth Physics, Allégt. 41, University of Bergen, 5007 Bergen, Norway \\ ${ }^{2}$ Institute of Solid Earth Physics, University of Bergen, 5007, Norway \\ ${ }^{3}$ Institute for Seismology and Volcanology, Hokkaido University, Sapporo 060, Japan \\ ${ }^{4}$ Earthquake Research Institute, University of Tokyo, Tokyo 113-0032, Japan
}

(Received April 11, 2002; Revised November 2, 2002; Accepted November 8, 2002)

\begin{abstract}
This paper describes the processing and analysis of semi-local OBS-data shot along a $122 \mathrm{~km}$ profile in the Vøring Basin, NE Atlantic margin, using both a high-frequency/short shot-spacing and a low-frequency/long shotspacing air-gun source. Spectral analysis of the data reveals that an important difference between the two sources used, is that the low-frequency source generates significantly more energy around $6 \mathrm{~Hz}$. This higher content of very low frequencies allows detection of arrivals to larger offsets for the low-frequency source. For the nearest offsets $(0-20 \mathrm{~km})$ the high-frequency source is able to resolve some more details than the low-frequency source, as far as the shallow to intermediate sedimentary levels are concerned. This is mainly caused by the fact that the high-frequency source has a much sharper primary pulse and reduced bubble pulse compared to the low-frequency source. The data quality can be significantly enhanced by use of band-pass filtering, trace mixing, FK (velocity) filtering, minimum phase predictive deconvolution, as well as Radon filtering. Inspection of particle diagrams documents S-wave splitting, interpreted as microcracks aligned vertically in the sedimentary section by the present day (slightly compressive) stress-field.
\end{abstract}

\section{Introduction}

On the Norwegian continental shelf, NE Atlantic, several regional crustal scale seismic experiments by use of Ocean Bottom Seismographs (OBS) have been performed in collaboration between University of Bergen and Hokkaido University. An extensive experiment involving Japanese OBSs was performed in 1988 off Lofoten, northern Norway (Fig. 1, Sellevoll et al., 1988). The analysis of these data has shown that this method in many cases provides information about the crustal structure not achievable through the study of seismic multichannel vertical-incidence data alone (Mjelde et al., 1992, 1993). Of particular importance is the ability of the OBS technique to reveal structures beneath a floodbasalt, which in this area is opaque using the multichannel reflection method. In addition, the horizontal components ensure reliable analysis of S-waves, which provides information about lithology, as well as anisotropy caused by fractures and aligned minerals (Mjelde et al., 1995).

In spite of the well documented efficiency of the method, only minor efforts have been made to investigate how the method can assist in more detailed investigations of sedimen-

\footnotetext{
*Present address: Earthquake Research Institute, University of Tokyo, Yayoi 1-1-1, Bunkyo-ku, Tokyo 113-0032, Japan.

** Present address: JAMSTEC, 2-15 Natsushima-cho, Yokosuka-city, Kanagawa 237-0061, Japan.
}

Copy right(c) The Society of Geomagnetism and Earth, Planetary and Space Sciences (SGEPSS); The Seismological Society of Japan; The Volcanological Society of Japan; The Geodetic Society of Japan; The Japanese Society for Planetary Sciences. tary basins and crystalline crustal structure. Deep structures (crystalline basement and the Moho) can be mapped with confidence from OBS data, but detailed imaging of structures is generally impossible due to the long distance between the OBSs (20-30 km) and shots (ca. $250 \mathrm{~m})$ used in regional scientific crustal studies. In addition, the seismic source generally used in such experiments is focused on low-frequencies $(5-20 \mathrm{~Hz})$, and its pulse is often contaminated by large bubbles.

To enlighten these aspects and to evaluate the resolution limits of OBSs used in mapping of crustal structures, an extensive experiment by use of twenty-five three-component OBSs deployed along a $122 \mathrm{~km}$ long profile was conducted in the central Vøring basin in 1992 (Fig. 1). This basin was influenced by intense magmatism during the early Tertiary opening between Greenland and Norway (e.g. Eldholm and Grue, 1994), making mapping of deep sedimentary and crystalline structures very difficult with multichannel reflection data.

The profile was acquired twice; first with a low-frequency source shot every ca. $250 \mathrm{~m}$. In the regional study only five of the twenty-five OBSs were used (OBS 1, 6, 13, 17, 20), whereas all OBSs were included in the semi-local (lowfrequency source) study. The profile was then shot with a high-frequency source fired every ca. $50 \mathrm{~m}$ (semi-local, highfrequency study). The modeling of the regional and semilocal data shot with the low-frequency source (both P- and S-waves), has been presented by Mjelde et al. (1997a, b) and 


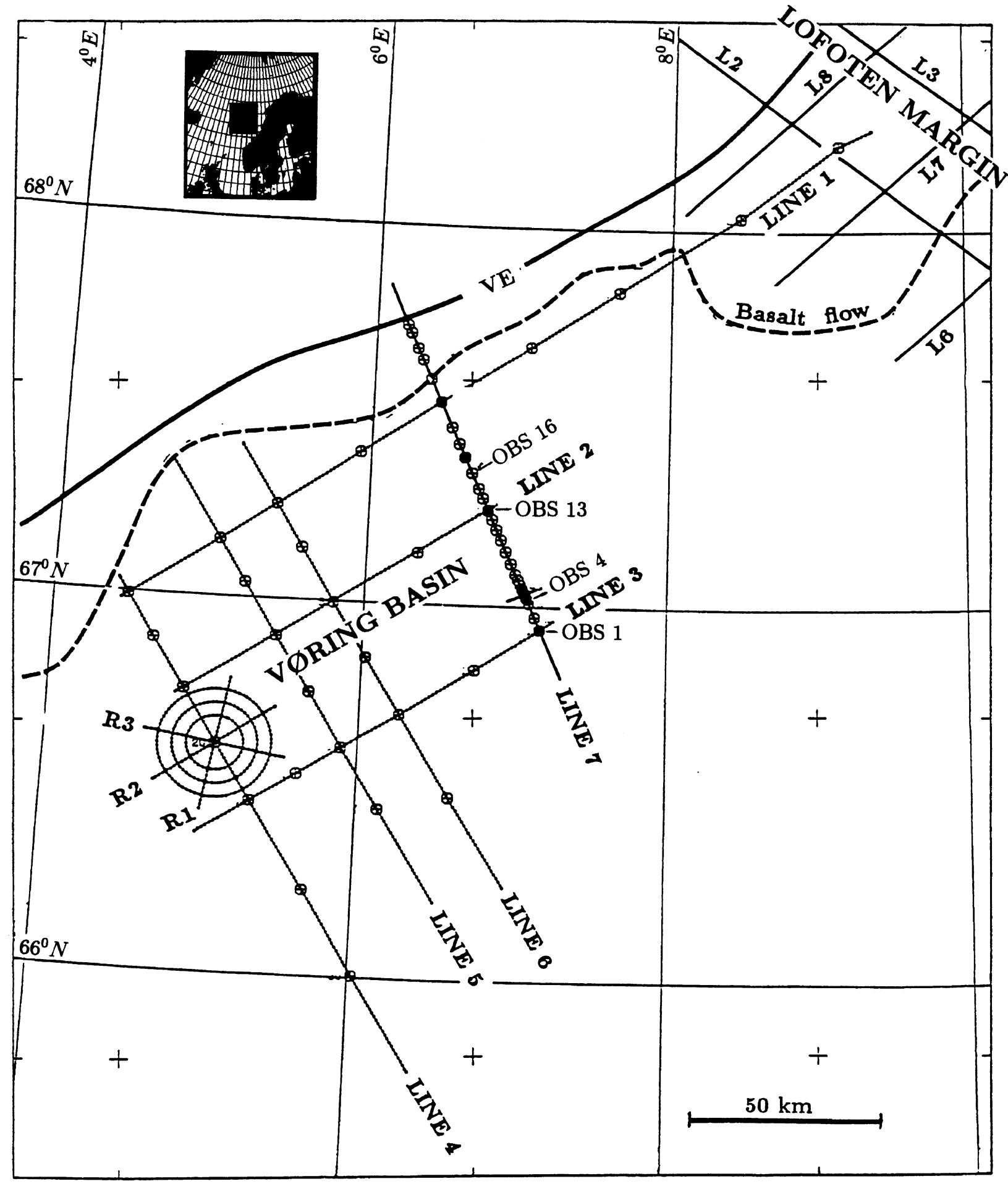

Fig. 1. The survey area with all profiles and OBS positions indicated. Line 7 represents the semi-local profile described in this paper. The landward limit of the early Eocene basalt flow, the Vøring Escarpment (VE), and parts of the profiles acquired off Lofoten in 1988 are also indicated.

Digranes et al. (1996). The main purpose of the regional study was to map the distribution of sills in the sediments, the deep sedimentary structures, the top of the crystalline basement, the distribution of an inferred lower crustal magmatic body, and the depth to the Moho. The purpose of the (lowfrequency source) semi-local study was to evaluate the accuracy of the regional method, and to evaluate the importance of closer OBSs spacing in a more detailed mapping of structures throughout the crust. The main reason for including the S-waves in the analysis was these waves' general ability to provide lithological information when combined with P-waves (e.g. Neidell, 1985).

The present paper describes the processing and analysis of the semi-local P- and S-wave (vertical and horizontal component) data shot with the high-frequency source. The purpose with the acquisition of this dataset was to evaluate the importance of low- versus high-frequencies in mapping at various depths, as well as the value of closer shot-spacing in terms of 


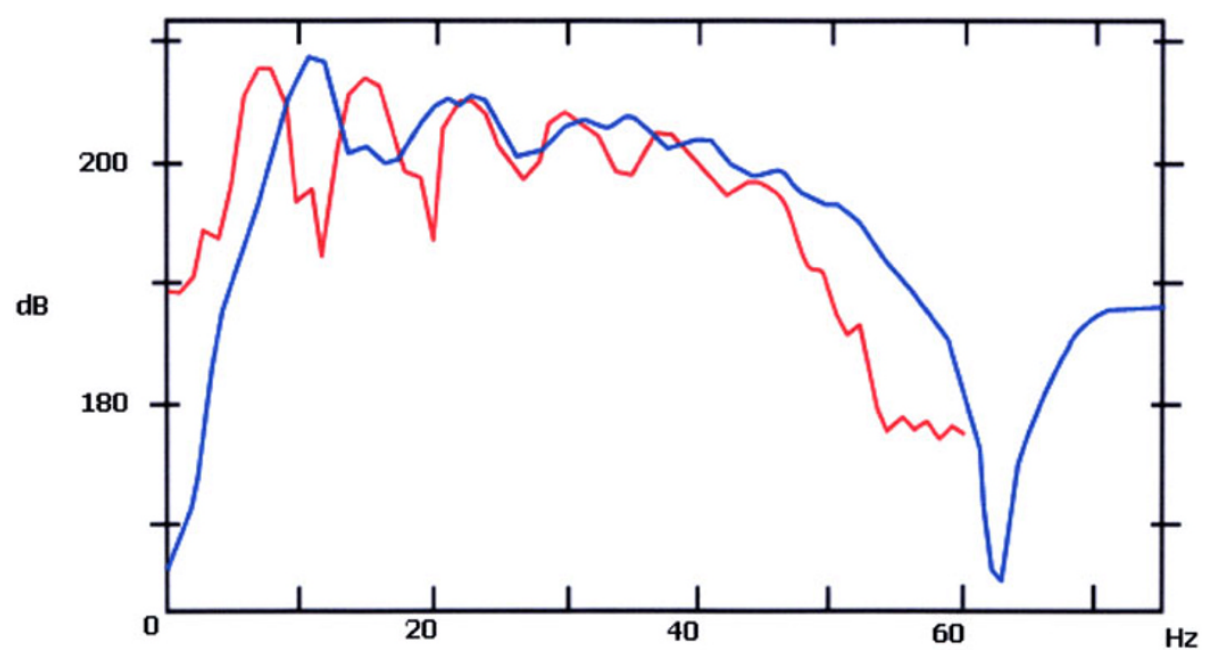

Fig. 2. Theoretical amplitude spectrum of far-field signature for the high-frequency source (blue) and low-frequency source (red). In order to allow comparison of the relative differences in amplitude versus frequency, the spectra have been adjusted for differences in total output power.
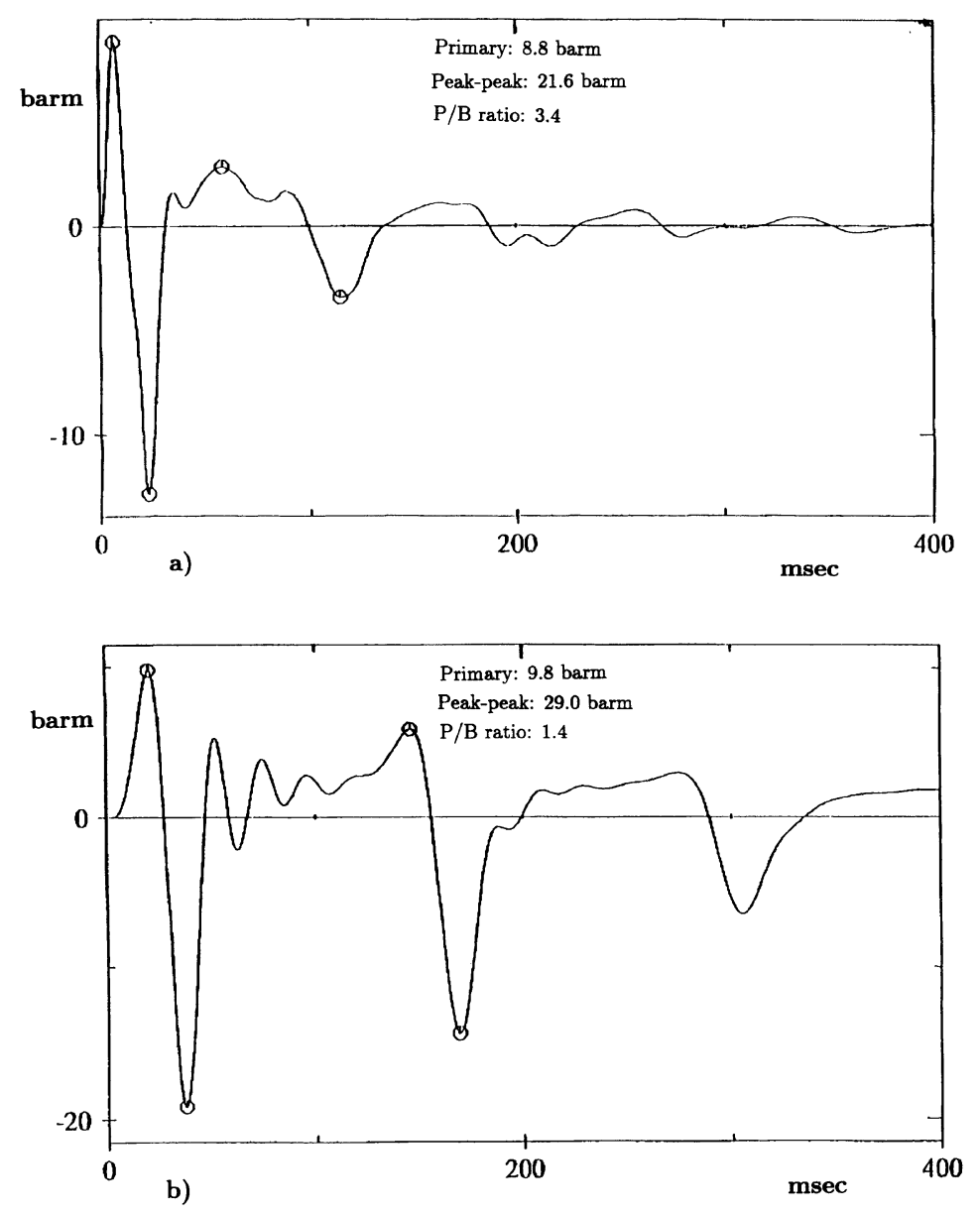

Fig. 3. Theoretical seismic pulse (far-field signature) for the high-frequency source in (a) and low-frequency source in (b).

enhanced resolution and possibilites for more sophisticated processing.

\section{Data Acquisition}

The location of OBSs and profiles shot during the experiment in the Vøring basin in 1992 are shown in Fig. 1. Each of the OBSs was deployed several times; a total of 75 OBS deployments along $\approx 1650 \mathrm{~km}$ in-line profiles were thus performed during the acquisition. The experiment was carried out in the period August 22 to September 241992 by use of R/V Håkon Mosby belonging to the University of Bergen. The experiment was divided in four parts; a regional survey along 7 profiles using 27 OBSs (Mjelde et al., 1997a), a local survey on one structure employing 20 OBSs deployed a sec- 
ond time (Berg et al., 2001), a circle-shooting around one of the OBSs deployed in the regional survey, and a semi-local experiment where 25 OBSs were employed a third time. This paper focuses on the data acquired during the semi-local survey.

Two different air-gun configurations were used during the experiment. Four equally sized Bolt $1500 \mathrm{C}$ air-guns with a total volume of $4800 \mathrm{in}^{3}$ (78.7 1), were used in all parts of the acquisition (Figs. 2-3). This high-energy source with main frequency spectrum in the range $5-40 \mathrm{~Hz}$, was used to allow mapping of deep structures. The second configuration consisted of two Bolt $1500 \mathrm{C}$ air-guns with waveshape together with five air-guns on a string with a total volume of $1956 \mathrm{in}^{3}$ (32.1 l) (Figs. 2-3). The size of these air-guns varied from 60 to $340 \mathrm{in}^{3}$. This air-gun configuration with main frequency spectrum in the range $8-42 \mathrm{~Hz}$, was used during the local and semi-local study, because of its increased content of higher frequencies and better pulse/bubble ratio. This source configuration was thus used to allow better mapping of shallow and intermediate crustal structures. One shot was fired every $2 \mathrm{~min}$. at about $250 \mathrm{~m}$ intervals when the low-frequency source was used, and every $1 \mathrm{~min}$. at about $50 \mathrm{~m}$ intervals for the high-frequency source. The source depth was $12 \mathrm{~m}$ in each case. The distance between each gun was ca. $4 \mathrm{~m}$, which implies linear interaction between the air-guns, and the extent of each air-gun array was limited, implying that both sources can be considered as point-sources.

The three-component OBSs used were developed at the Institute for Seismology and Volcanology, Hokkaido University, and Laboratory for Earthquake Chemistry, Tokyo University. These analogue instruments equiped with 4.5 $\mathrm{Hz}$ geophones could record continuously for 14 days within the $1-30 \mathrm{~Hz}$ frequency range $(-3 \mathrm{~dB})$. Two different tapespeeds were used during the experiment; a low tape-speed for the regional study, limiting this survey to frequencies below about $20 \mathrm{~Hz}$, and a high tape-speed for the semi-local and local studies, allowing detection of frequencies up to ca. $40 \mathrm{~Hz}$. The reader is referred to Kanazawa (1993) and Mjelde et al. (1997a) for more details concerning the instruments used.

The OBSs recorded continuously throughout the acquisition of the semi-local dataset. The positions and thus the state of coupling between the instruments and the seafloor were the same during the shooting with both sources. The shot-direction was also the same (from NW to SE), assuring that differences in the two datasets can be related to three aspects only; the ambient noise level, the sources, and the shot-distance (in average $233 \mathrm{~m}$ for the low-frequency data, and $55 \mathrm{~m}$ for the high-frequency data).

\section{Regional versus Semi-Local Models}

The regional kinematic $\mathrm{P}$-wave model derived by raytracing of 5 OBS vertical components, acquired by use of the low-frequency source, is shown in Fig. 4(a) (Mjelde et al., 1997a). The ray-tracing software employed has been developed by Norsk Hydro (Pajchel et al., 1989). The basins and highs down to the 'lowest reflector' (lr) have been accurately mapped by a multichannel reflection profile acquired earlier, whereas the deeper layers have been included based on the OBS-data. The high-velocity sill-intrusions in the sedimen- tary section, indicated as thin, darker shaded layers in the model, also result from the modeling of the OBS-data. These sill-intrusions are assumed to be emplaced during the early Eocene break-up between the European and north American plates. The high-velocity lower crust, which is inferred to represent intrusions in the lower crust (magmatic underplating), are also included in the model based on the OBS-data.

The semi-local P-wave model derived by ray-tracing of all 25 OBS vertical components acquired along the same profile (with the same source) is shown in Fig. 4(b) (Mjelde et al., 1997b). Two observations are clear by comparing the regional and semi-local models; firstly, the over-all structures are very similar, proving that the regional method provides reliable regional models, and secondly, that the semi-local data provide more detailed information in all parts of the model. Whether these 'details' are important enough to suggest use of the more time-consuming and expensive semilocal experiment set-up, would depend on the scientific objectives in each specific case.

\section{Data Recovery}

All twenty-five OBSs used in the semi-local study discussed in this paper were recovered from the sea-floor, but the tape from OBS 2 was blank due to malfunctioning of the tape recorder. This applies, of course, to the shooting with both sources. In addition, a few traces for each OBS could not be recovered. The reasons for the loss of these traces can be related to problems with the seismic source, as well as minor anomalies in the $\mathrm{A} / \mathrm{D}$ conversion procedure. For the shooting with the low-frequency source 2-3 traces were lost for each OBS, with the exception of OBS 13 and 17, for which 27 and 93 traces were lost, respectively. This implies a total loss of $5.3 \%$ for the low-frequency data. For the high-frequency data, the variations in the loss of data were higher; most of the OBSs lack 2-4 traces only, but the data from OBS 17 could not be A/D converted due to strong noise of unknown origin. For the remaining OBSs, the largest loss of data is found on OBS 9 (63 traces). The total data-loss for the high-frequency data is $8.5 \%$. It is important to underline that this limited loss of data (for both sources) does not significantly hamper the attempts to evaluate the differences between the acquisitions, nor does it significantly reduce the amount of geological information that can be extracted from the datasets.

\section{Data Processing}

The OBS-data were A/D converted at Hokkaido University in Sapporo, and further processing were performed at the Institute of Solid Earth Physics (IFJ), University of Bergen. The digital data-processing of the low-frequency vertical components was limited to frequency filtering only, as far as the semi-local P-wave modeling was concerned (Mjelde et al., 1997b). For the horizontal components, spiking deconvolution was applied in addition, in order to assure more accurate detection of S-wave first breaks (Digranes et al., 1996).

In the following, the Common Receiver Gather processing of the semi-local data acquired by use of the high-frequency source will be described. The processing has been performed in detail on OBS $1,4,13$, and 16 , covering different struc- 
a) Distance $(\mathrm{km})$
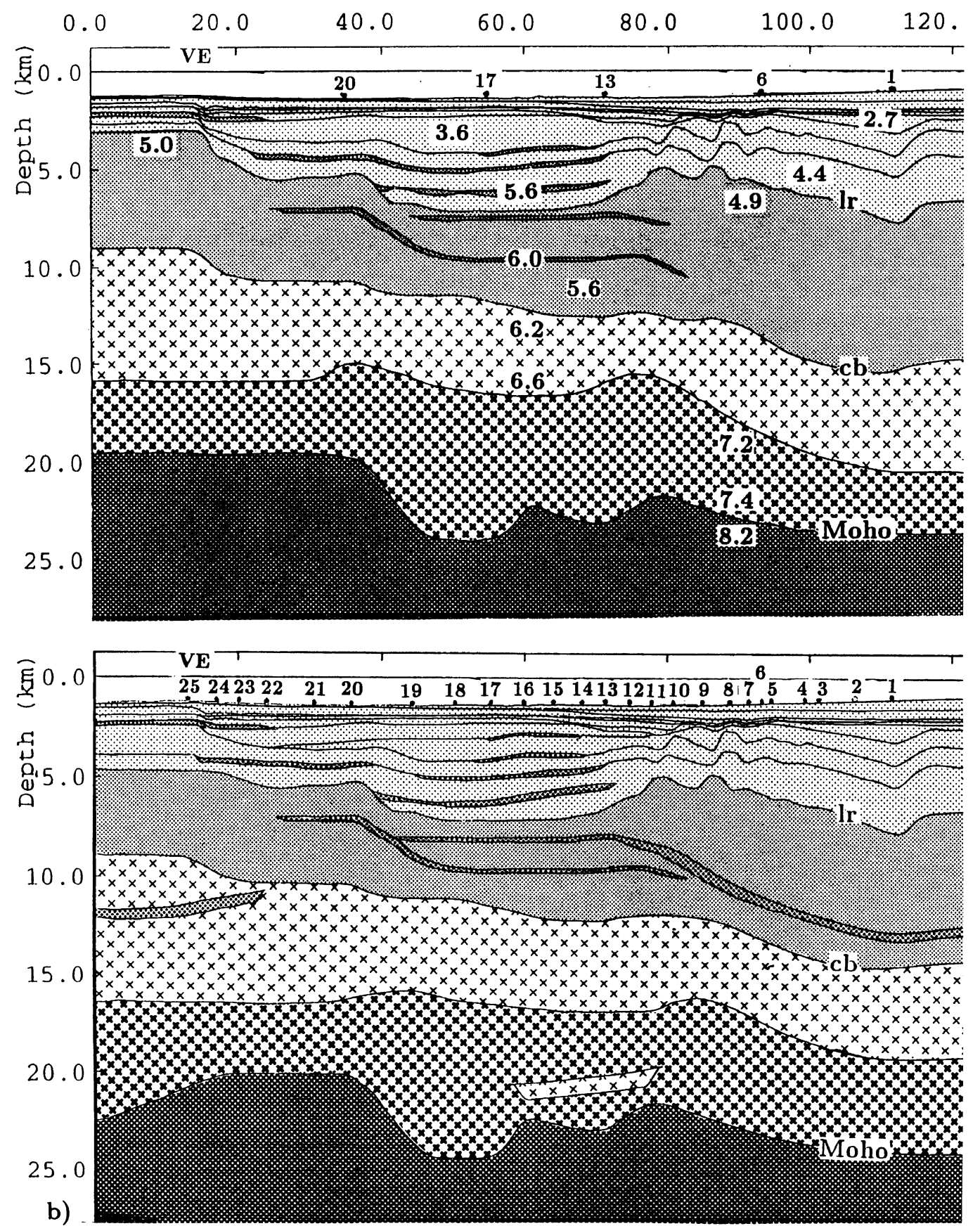

Fig. 4. (a) The regional model for profile 7, with seismic P-wave velocities (in $\mathrm{km} / \mathrm{s}$ ) for some main layers indicated (from Mjelde et al., 1997a). 'lr' refers to the deepest interface mapped from multichannel reflection data, and 'cb' is interpreted as the top of the crystalline basement. (b) The semi-local model derived from the data acquired with the low-frequency source. The velocities are very similar to those in (a) (from Mjelde et al., 1997b).

tures along the profile. To limit the number of figures in the paper, and since the processing of the four OBSs did not reveal significant differences, we will focus on the processing of OBS 1. Unless otherwise stated, the processing schemes described have been applied to the vertical-, as well as to both horizontal components. The processing has been performed by use of the PROMAX software. Detailed background for each processing step is not given, since only standard routines for processing of surface seismic data have been applied.

\subsection{Analysis of frequencies, amplitudes and noise}

In order to study the amplitudes of the seismic signal as function of frequencies and offset, as well as the noise, power-spectra have been analysed for several different timewindows for all offsets (Fig. 5). The noise can be classified into four different groups; noise caused by water currents, microseisms, instrumental noise and man-made/biotic noise. The noise from water currents and microseisms is manifested in the $0-3 \mathrm{~Hz}$ frequency-band (Fig. 5(b)). Small amounts of such low-frequency noise is generally present in the OBS data (Fig. 6(a); Webb and Cox, 1986; Trevorrow 
a)

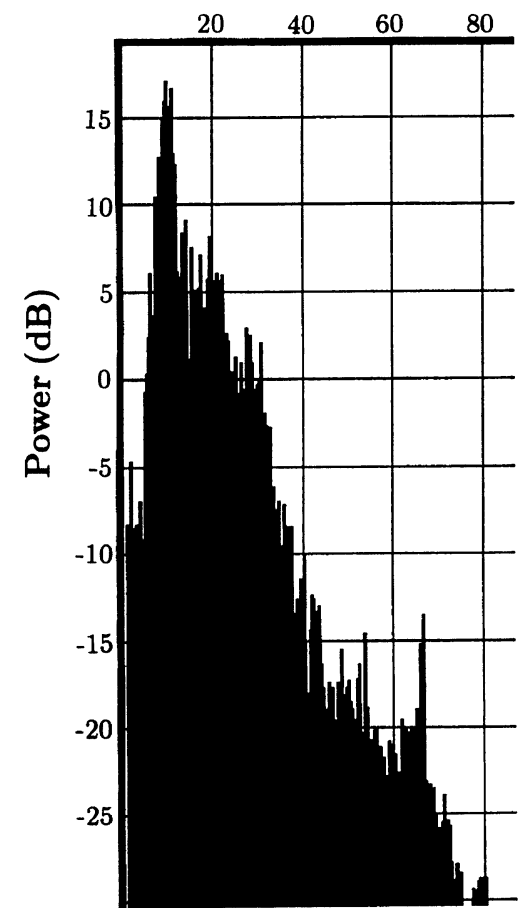

b)

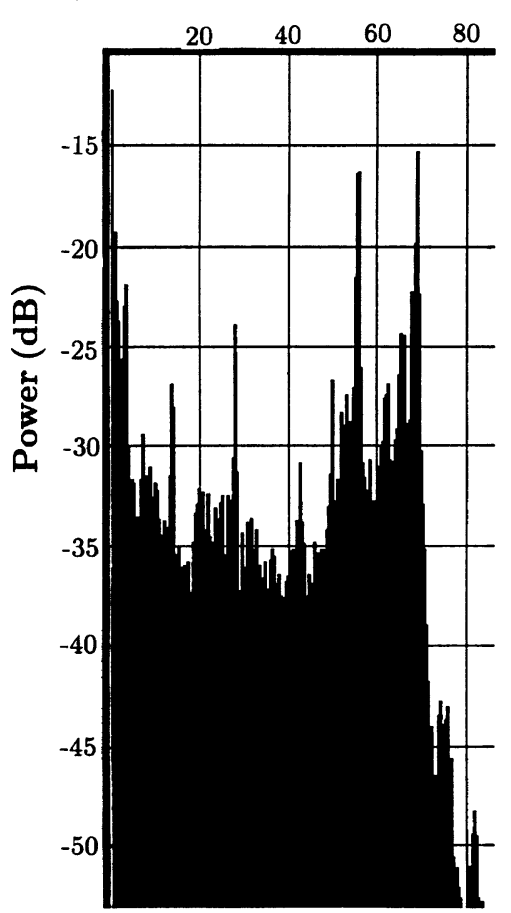

c) Frequency $(\mathrm{Hz})$

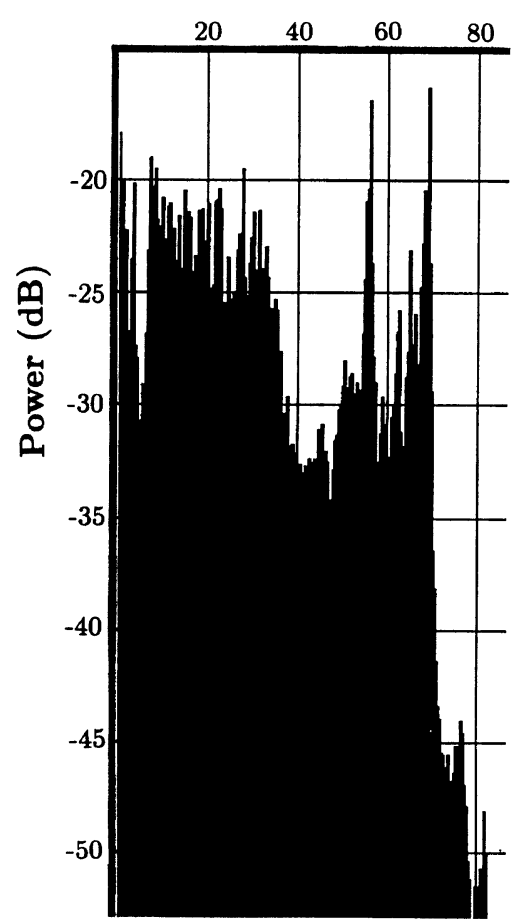

Fig. 5. Examples of typical amplitude spectra for OBS 1, shot with the high-frequency source. (a) Signal spectrum for traces 1989-2016, non-reduced time-window 3.1-5.1 s. (b) Low- and high-frequency noise spectrum for traces 298-307, non-reduced time-window 5-8 s. (c) Seismic frequency noise spectrum for traces 348-357, non-reduced time-window 2-5 s. As dB is relative unit, only relative comparisons between the vertical axis of the three plots can be made.

et al., 1989). In addition to this low-frequency noise, several peaks are observed in the $50-70 \mathrm{~Hz}$ frequency-range (Fig. 5(b)). These frequencies are recorded with large distortions, since the analogue tape recorder with the tape-speed used cannot record frequencies above $40 \mathrm{~Hz}$ correctly. The high-frequency peaks are most likely instrumental noise.

The low- and high-frequency noise do not represent any problems for the analysis of the data, since these frequency bands can be effectively removed using a band-pass filter. For many traces, however, large amplitude noise is present throughout the seismic frequency-window (ca. 5-35 Hz). Note the much higher level of noise for this band if frequencies in Fig. 5(c), compared with Fig. 5(b). This noise is either caused by a nearby seismic vessel (no such vessels were reported to be present in the area) or a vessel of another type (cargo/fishery). Moreover, it cannot be excluded that parts of the noise might represent water-arrivals from our own previous shots, although the magnitude and spatial distribution of the noise precludes this component to be large. The noise appears as strongly dipping coherent events that are best observed in the high-frequency data, due to the closer shot-spacing for these data (Fig. 8(a)). We will in the following refer to this noise as seismic, since it is constrained within our usable seismic bandwidth. This seismic noise do not represent any severe problem as far as the quality of the OBS-data is concerned, since it can be attenuated by processing, and since its dip differs significantly from that of the real seismic arrivals recorded on the OBSs.

The seismic noise induces a problem, however, when the decay of the amplitudes for different signal-frequencies are investigated, following the procedure described by Mjelde et al. (1997c). Figures 7(a) and (b) shows the power of the three dominant signal frequency-peaks, 6,10 and $18 \mathrm{~Hz}$, as function of offset. The power has been calculated in a $2 \mathrm{~s}$ window covering the first arrivals, as well as lower amplitude secondary arrivals. In Figs. 7(c), (d) the plots have been corrected for seismic noise. This correction is performed as follows; for traces with no apparent seismic noise, the power in the $3-40 \mathrm{~Hz}$ range is observed to be about -37 $\mathrm{dB}$ (ambient noise-level). For traces where the seismic noise is observed, it is assumed that the level of the ambient noise remains constant across the signal time-window. The level of the seismic noise is then measured for the three investigated frequency-peaks (from the noise spectra), and subsequently subtracted from the signal power-spectrum. It is important to notice that the correction is not performed for the near-zero offsets, since the short travel-time of the direct wave prevents accurate estimates of the noise-level for these traces.

Since the ambient noise-level is found to be about -37 $\mathrm{dB}$, the level of seismic signals must be above about -30 $\mathrm{dB}$ to be clearly observed. Figure 7(d) shows that the amplitudes for all three frequency-peaks are below $-30 \mathrm{~dB}$ beyond about $55 \mathrm{~km}$ offset (arrival 3) for the high-frequency source. For the low-frequency source (Fig. 7(c)) the same is true for the 10 and $18 \mathrm{~Hz}$ peaks, but the $6 \mathrm{~Hz}$ peaks contain detectable energy to the maximum offset $(72 \mathrm{~km}$; arrival 1). Important differences between the two sources are that the low-frequency source is more powerful than the highfrequency source due to its larger volume, and it generates significantly more energy around $6 \mathrm{~Hz}$ (ca. $11 \mathrm{~dB}$, Fig. 2), 
NW

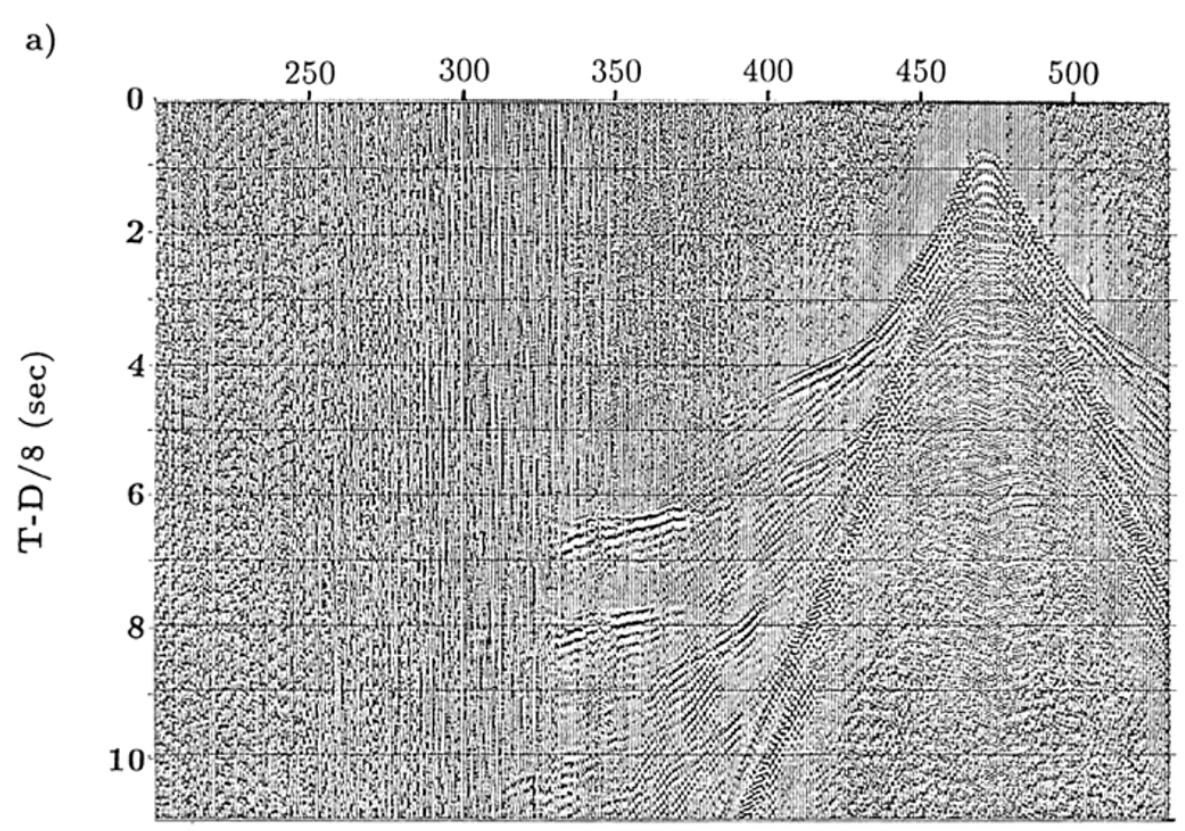

a)

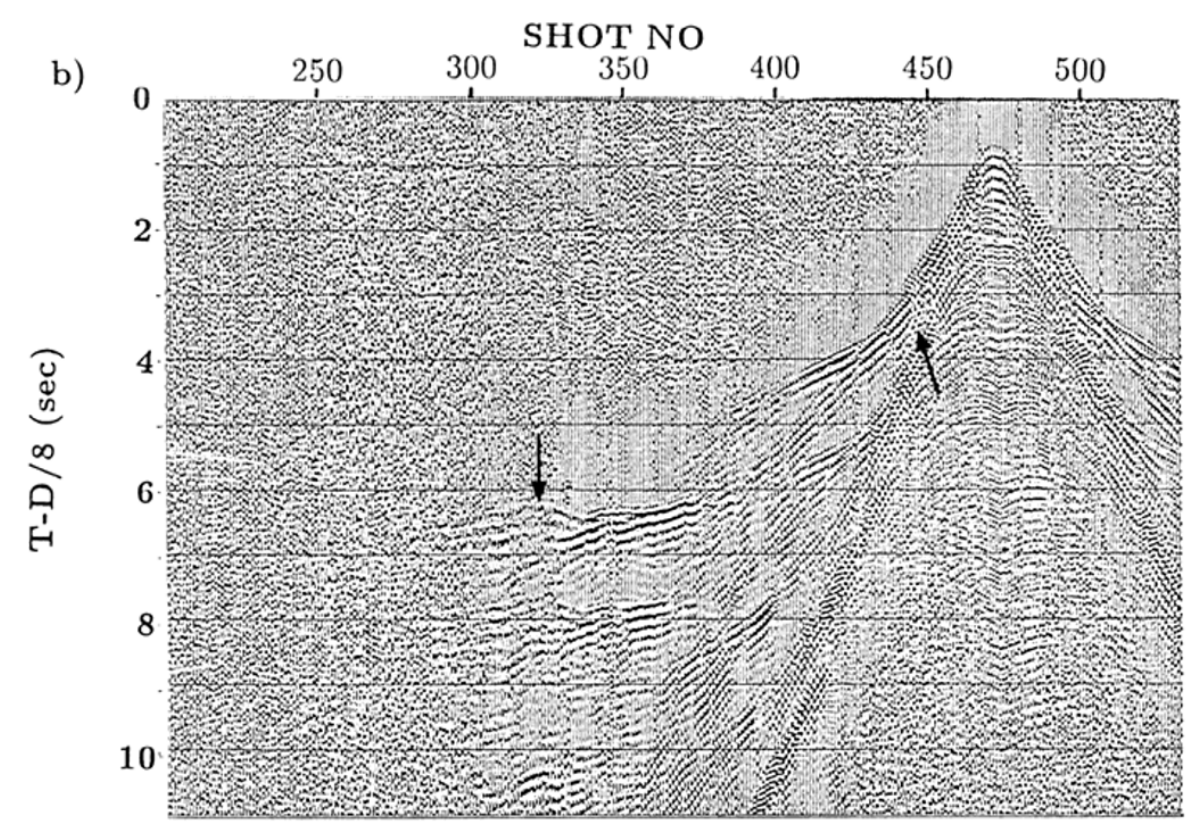

Fig. 6. (a) Vertical high-gain component of OBS 1, low-frequency data. Plotted with Automatic Gain Control (AGC) window of $4 \mathrm{~s}$ length, and $8.0 \mathrm{~km} / \mathrm{s}$ reduction velocity. (b) Same as (a), but 5-12 Hz band-pass filtered in addition. Notice that the far-offset arrival between shotpoints 290 and 340 appears much more clearly after filtering. The arrow at ca. 450 indicates an arrival that is more clearly defined in the data acquired with the high-frequency source (compare with Fig. 8(b)), whereas the far-offset arrival at ca. 320 is clearly observable only in the low-frequency data.

which allows detection of arrivals to larger offsets. This can be seen by comparing the high-frequency data shown in Fig. 8 with the low-frequency data presented in Fig. 6; the low-frequency data reveal a strong arrival at ca. $6.5 \mathrm{~s}$ depth, between shotpoints 290 and 340, which cannot be seen in the high-frequency data.

\subsection{Differences between sources and shot-spacing}

The difference in low-frequency content between the two sources implies that coherent seismic energy can be observed to larger offset on the data acquired with the low-frequency source. Although the shot-spacing is about 4 times larger for the low-frequency data, arrivals can generally be observed to larger offset in these data; to $59 \mathrm{~km}$ (mean maximum offset for all OBSs), compared to $53 \mathrm{~km}$ for the high-frequency data. The maximum offset for a single OBS is $88 \mathrm{~km}$ for the low-frequency data and $63 \mathrm{~km}$ for the high-frequency data. (All twenty-five OBSs have been included in this analysis.)

In order to investigate how the differences in the sources qualitatively affect the seismic data, the high-frequency data has been plotted using every 4 th trace only (Fig. 8(b)). For the nearest offsets (reflections and refractions from the shallow to intermediate sedimentary levels) the high-frequency source is clearly able to resolve some more details than the low-frequency source (compare with Fig. 6(b)). This is 
a)

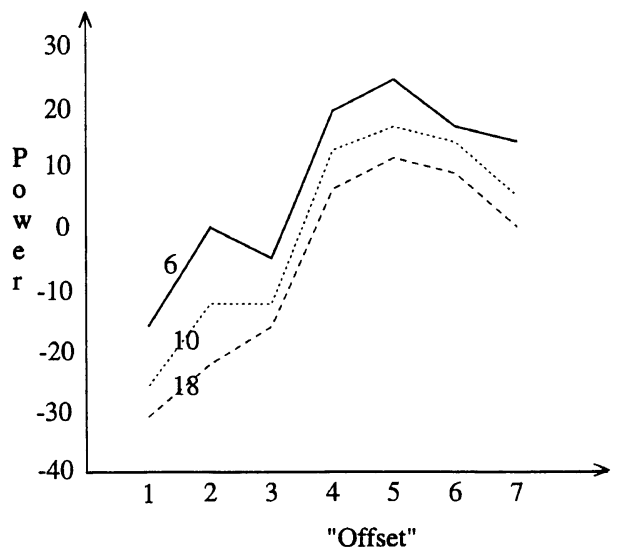

c)

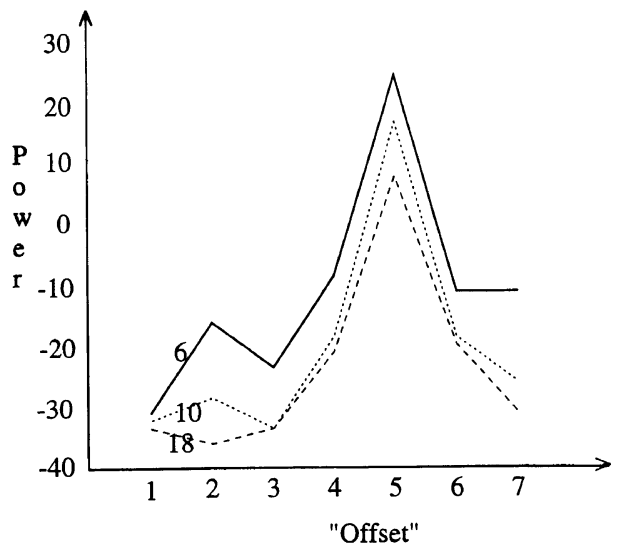

b)

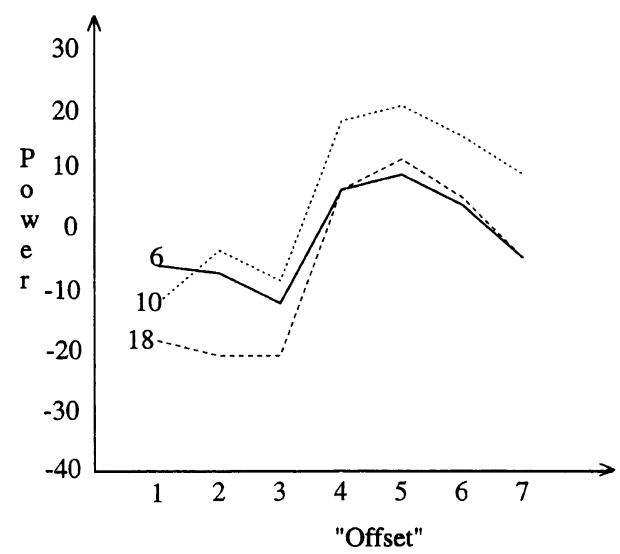

d)

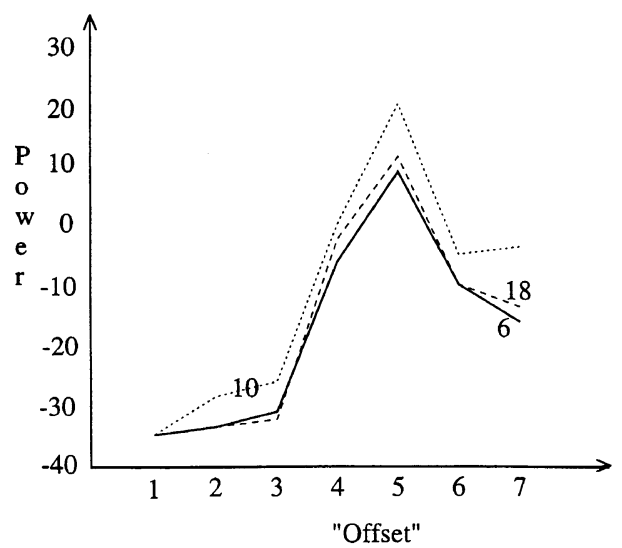

Fig. 7. Power spectra for the three frequency peaks studied for OBS 1; 6, 10 and $18 \mathrm{~Hz}$. (a) and (b) show the uncorrected estimates for the low- and high-frequency source, respectively. (c) and (d) show the corresponding corrected curves (see text). 'Offset' refers to a representative selection of arrivals for various offset that have been studied; arrival 1 being the fartest offset arrival to the NW, arrival 5 represents the near offsets, and arrival 7 represents offsets close to the SE end of the profile. Detailed offset ranges (shot no) for the low-frequency data, arrivals 1-7: 298-307, 348-357, 379-388, 429-438, 456-465, 487-496, 513-522. Detailed offset ranges (shot no) for the high-frequency data, arrivals 1-7: 1359-1395, 1609-1645, 1766-1802, 1989-2016, 2070-2110, 2150-2183, 2210-2242.

mainly caused by the fact that the high-frequency source has a much sharper primary pulse and reduced bubble pulse compared to the low-frequency source. In addition, a slightly increased level of higher frequencies (above $15 \mathrm{~Hz}$; Fig. 7) also contributes to the differences in resolution.

Plotting every 4th trace of the high-frequency data generally causes a decrease in the maximum offset of clearly identifiable arrivals, compared to the complete seismic section. Decreasing the spacing between the shots thus clearly increases the useful penetration depth of the survey (Fig. 8). However, the higher content of frequencies around $6 \mathrm{~Hz}$ in the low-frequency data assures larger penetration depth for that survey, in spite of the coarser shot interval applied.

\subsection{Trace mixing}

Trace mixing is a method that can be used to enhance the coherency of weak far-offset arrivals, and hence decrease the uncertainty in the interpretation of these arrivals (e.g. Samson et al., 1995). When applied to data reduced by $8 \mathrm{~km} / \mathrm{s}$, trace mixing will enhance arrivals that propagate with an apparent velocity of about $8 \mathrm{~km} / \mathrm{s}$ (horizontally) and reduce the amplitudes of dipping arrivals.
The trace mixing consisted of multiplying the trace samples by the following weights: 1, 2, 1 for the low-frequency data, and 1, 2, 3, 4, 5, 4, 3, 2, 1 for the high-frequency data. The accumulated weighted sample is subsequently normalized by the sum of the weights. These number of traces have been used in order to sum traces for comparable offsets. Figure 9(b) shows an example of the result of weigthed trace mixing, where 3 traces have been applied in the mixing for the high-frequency data (every 4 th trace plotted). Comparing with the plot with no trace mixing applied (Fig. 9(a)), it is clear that low-velocity dipping events have been attenuated, and that the continuity of the far-offset arrivals has been increased. Furthermore, the far-offset arrival seen between shotpoints 290 and 340 in the low-frequency data (Fig. 6(b)), but not observed in the high-frequency data for the same offsets (between shotpoints 1350 and 1550; Fig. 9(a)), can be weakly distinguished after trace mixing.

"Harder" mixing by use of more than 3 traces ( 9 for the high-frequency data) causes a further increase in the continuity of far-offset arrivals, but this apparent enhancement of the data cannot be considered as real, since this filtering also 

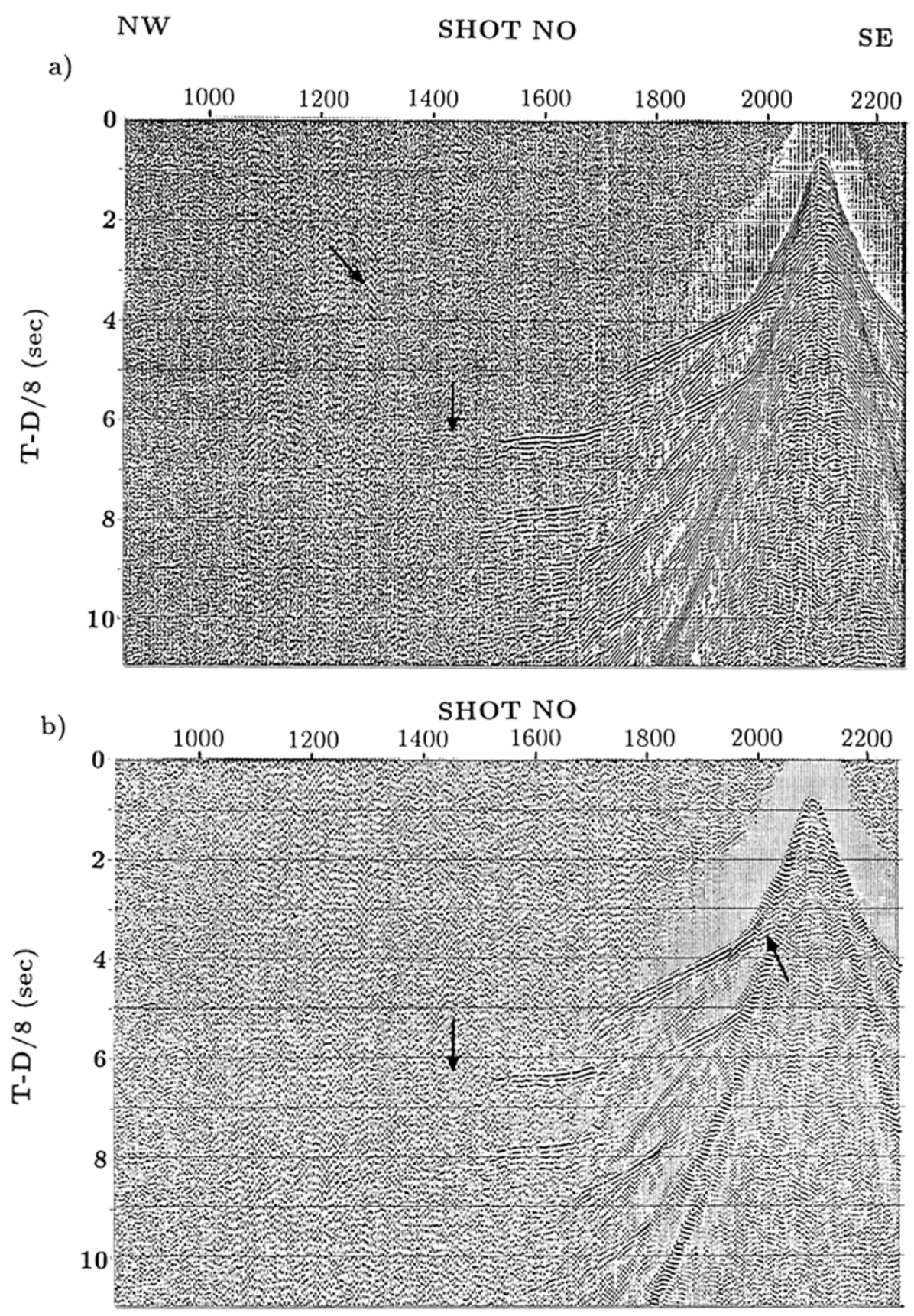

Fig. 8. (a) Vertical high-gain component of OBS 1, high-frequency data. Plotted with $4 \mathrm{~s} \mathrm{AGC,} 8.0 \mathrm{~km} / \mathrm{s}$ reduction velocity, and 5-12 $\mathrm{Hz}$ band-pass filter. The arrow at ca. 1450 indicates an arrival that is weakly observable (compare with Fig. 6(b)), and the arrow at ca. 1250 shows an axample of 'seismic noise'. (b) Same as a), but every 4th trace plotted only. The arrow at ca. 2000 indicates an arrival that is more clearly defined than in the data acquired with the low-frequency source (compare with Fig. 6(b)). The arrow at ca. 1450 shows that the arrival weakly observable in (a), cannot be discerned when every 4 th trace only is plotted.

induces similar coherency within the noise. In addition to the trace mixing described above, the mixing has also been applied along other dips, i.e. on data reduced with velocities below and above $8 \mathrm{~km} / \mathrm{s}$, without apparent enhancement of the data.

One limitation of the applied trace mixing is that it requires arrivals to be reasonably horizontal across the mixed traces. For our complicated dataset this requirement is only partly fulfilled. It must thus be expected that this kind of processing would be more successful when applied to data from geologically simpler areas.

\subsection{FK (velocity) filtering}

The high-frequency data are spatially aliased to a small degree only, consequently arrivals with velocity above about $1.5 \mathrm{~km} / \mathrm{s}$ can be removed by filtering in the FK (frequencywavenumber) domain. The long distance between the traces for the low-frequency data, however, causes spatial aliasing for velocities below about $5.5 \mathrm{~km} / \mathrm{s}$.

Figure 10 shows an example where both the low-velocity water-arrivals and high-velocity crustal arrivals have been attenuated by use of FK filtering. Note a clear enhancement in amplitude for arrivals with intermediate velocities. 

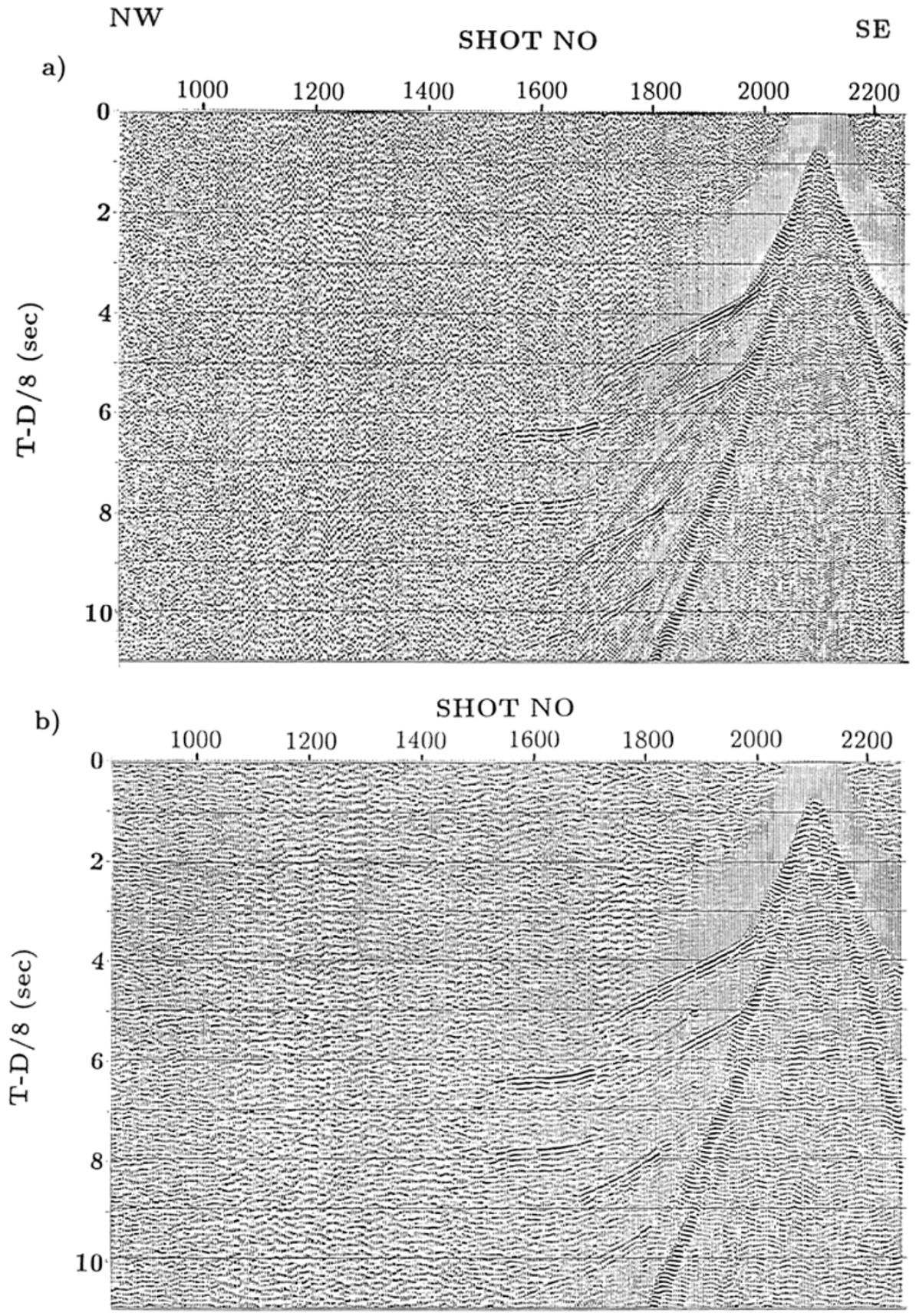

Fig. 9. (a) Vertical high-gain component of OBS 1, high-frequency data. Every 4 th trace plotted with $4 \mathrm{~s} \mathrm{AGC,} 8.0 \mathrm{~km} / \mathrm{s}$ reduction velocity, and $5-12 \mathrm{~Hz}$ band-pass filter. (b) Same as (a), but with trace mixing ( 3 traces) in addition. Notice that the deep far-offset arrival clearly seen in Fig. 6(b) can be seen, although weakly, between trace no. 1350 and 1550.

\subsection{Deconvolution}

Figure 11(b) shows an example of high-frequency data after deconvolution, compared to the non-deconvolved data in Fig. 11(a). The deconvolution applied is minimum phase predictive deconvolution with $500 \mathrm{~ms}$ operator length and $32 \mathrm{~ms}$ prediction gap. The design window follows the first arrival, and its length is $4 \mathrm{~s}$ from about $100 \mathrm{~ms}$ before the first arrival.

The deconvolution applied clearly removes "ringing" from the data, and the onset of the different arrivals can be interpreted with larger certainty. This is true for both datasets, although the effect is larger for the high-frequency data.

\subsection{Radon filtering}

Filtering by use of the 'slant stack' Radon transform, where the $\mathrm{x}-\mathrm{t}$ data are transformed into the intercept-time and ray-parameter domain, muted, and subsequently transformed back into the $\mathrm{x}$-t domain, is a method that can be used to attenuate arrivals with various dips at different arrivaltimes. Figure 12(b) shows an example of data after application of such a filter, in this case aimed for better resolution of deep high-velocity arrivals. After filtering a deep (9.5 s) high-velocity arrival, barely interpretable before filtering (Fig. 12(a)), is clearly observable in the data. The arrival is not a multiple, since its apparent velocity is at least $1 \mathrm{~km} / \mathrm{s}$ higher than that of earlier arrivals. 


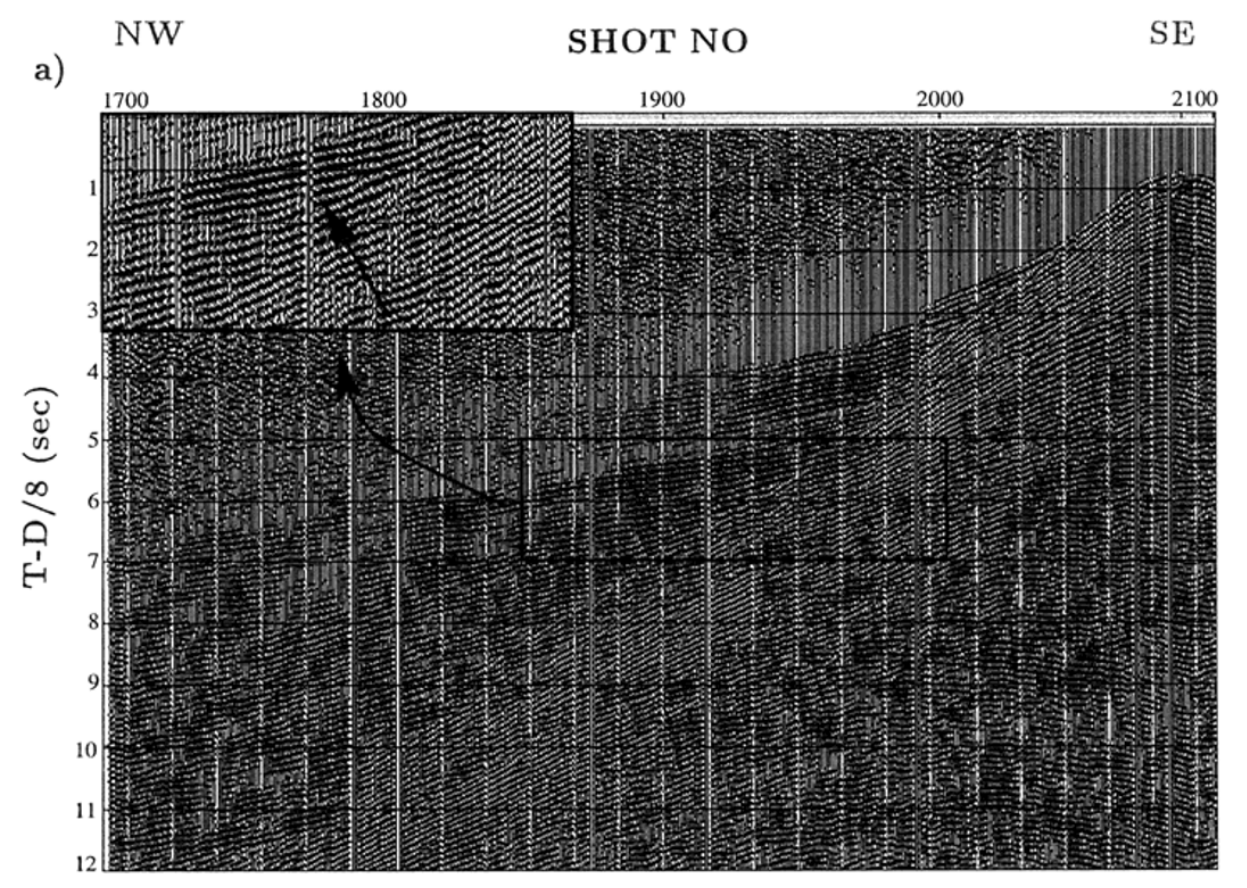

b)

SHOT NO

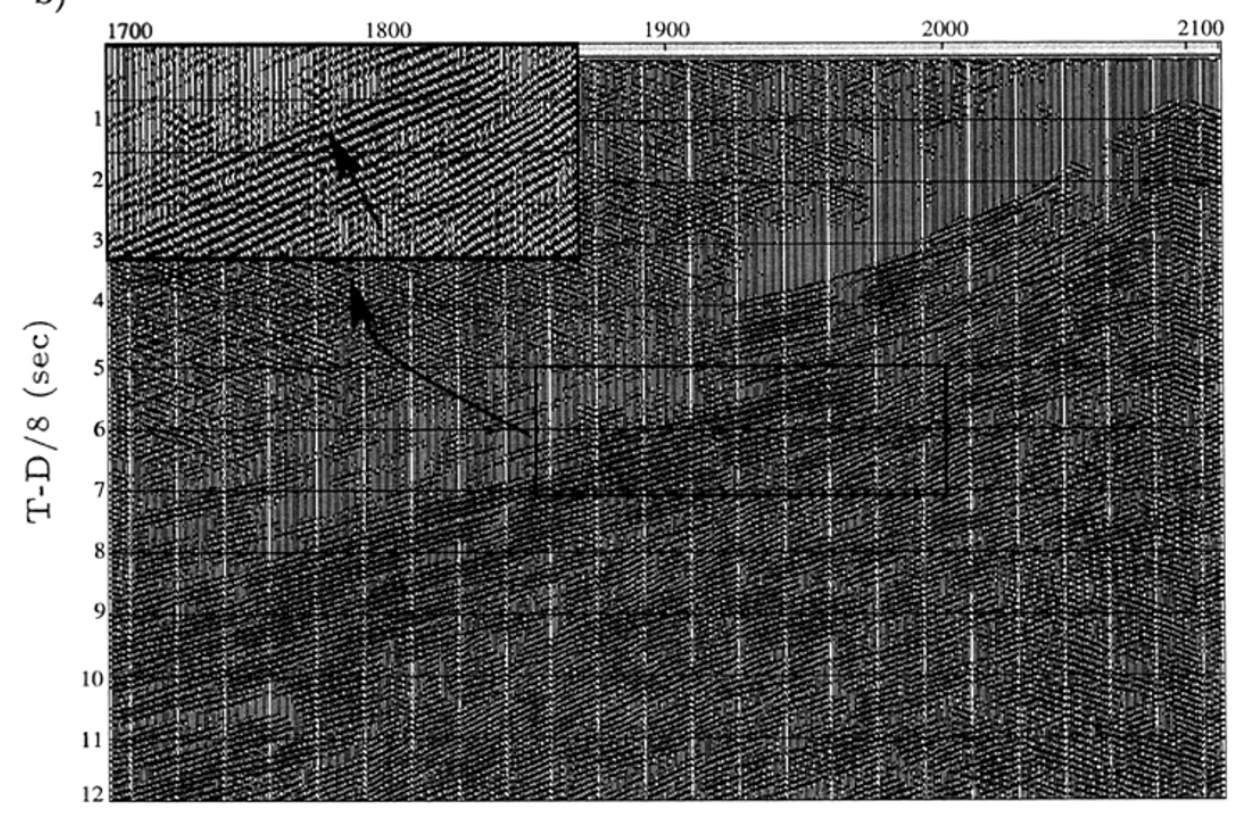

Fig. 10. (a) Horizontal high-gain component (channel 1) of OBS 1, high-frequency data. Plotted with $4 \mathrm{~s} \mathrm{AGC,} 8.0 \mathrm{~km} / \mathrm{s}$ reduction velocity, $5-14 \mathrm{~Hz}$ band-pass filter and trace mixing ( 3 traces). (b) Same as (a), but an FK filter removing apparent velocities below $2 \mathrm{~km} / \mathrm{s}$ and above $5 \mathrm{~km} / \mathrm{s}$ has been applied in addition. Notice the much clearer appearence of the intermediate velocity arrivals.

\subsection{Multichannel processing}

Conventional multichannel processing has been successfully performed on the local dataset, which was acquired by use of the high-frequency source and twenty OBSs (Berg et al., 2001; see Section 2). The shot- and receiver spacing were 50 and $200 \mathrm{~m}$, respectively. The main differences from standard multichannel processing resulted from the more complex geometry; the depth of the OBSs varied slightly, and the distance between the OBSs were not constant. The location of the OBSs on the seafloor were determined to within $20 \mathrm{~m}$ uncertainty by use of acoustic tri- angulation (Shiobara et al., 1997). The reader is refered to Berg et al. (2001) for details concerning the multichannel processing of the local dataset. The quality of the horizontal component stack allowed interpretation of S-wave reflectors on hydrocarbon reservoir scale to be made. These reflectors were better imaged on the vertical component (P-wave) stack (Fig. 15), but the quality of these processed data were not as high as that of the multichannel surface seismic data acquired earlier (Mjelde et al., 1997a).

The same multichannel processing scheme has been attempted on the high-frequency semi-local dataset, but with 
a) NW SHOT NO

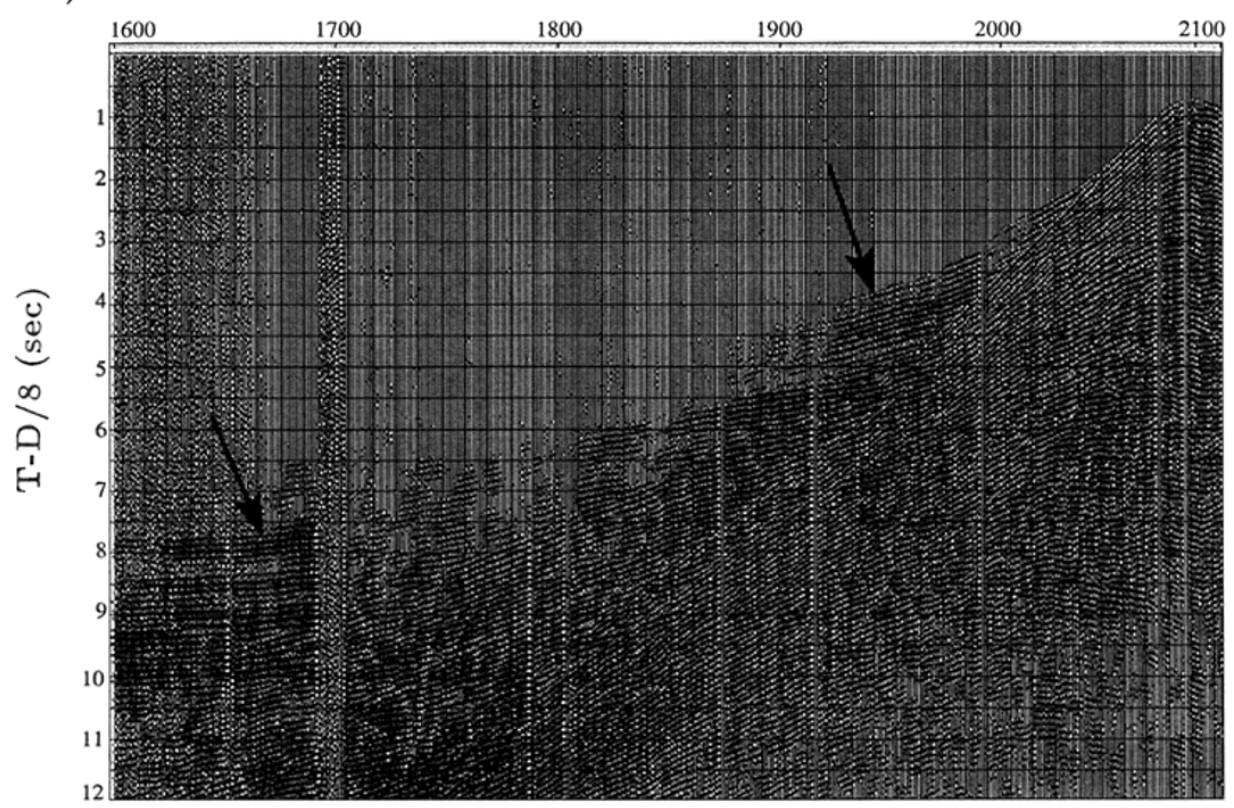

b) SHOT NO



Fig. 11. (a) Horizontal high-gain component (channel 1) of OBS 1, high-frequency data. Plotted with $4 \mathrm{~s} \mathrm{AGC,} 8.0 \mathrm{~km} / \mathrm{s}$ reduction velocity, and 5-14 Hz band-pass filter. (b) Same as (a), but with predictive deconvolution in addition. Notice the reduction of 'ringing'.

limited success due to the coarse OBS spacing. Although it cannot be excluded that more sophisticated multichannel processing of the semi-local data may provide more postive results, it is recommended that the receiver spacing is kept below ca. $2 \mathrm{~km}$ in multichannel studies.

\section{Hodogram Analysis}

Complete use of three-component seismic data includes an analysis of particle diagrams, or hodograms. Such analysis often reveals S-wave anisotropy, that could result from fluid-filled microcracks aligned vertically by the present day stress-field (e.g. Crampin, 1990). In such an anisotropic media an incoming S-wave would split into two S-waves, one polarized along the microcracks and one polarized perpendicular to the microcracks. The wave polarized along the microcracks will propagate with higher velocity, inducing a characteristic splitting of the waves that can be observed in hodograms.

In order to facilitate the analysis, the horizontal component high-frequency data have been rotated into in-line (along the shot profile) and cross-line (perpendicular to the profile) components, using the polarization of the direct (Pwave) water-arrival. The uncertainty in such rotations for this dataset have been estimated to $\pm 5 \%$ by Digranes et al. (1996).

Figures 13 and 14 summarize the results from the anal- 

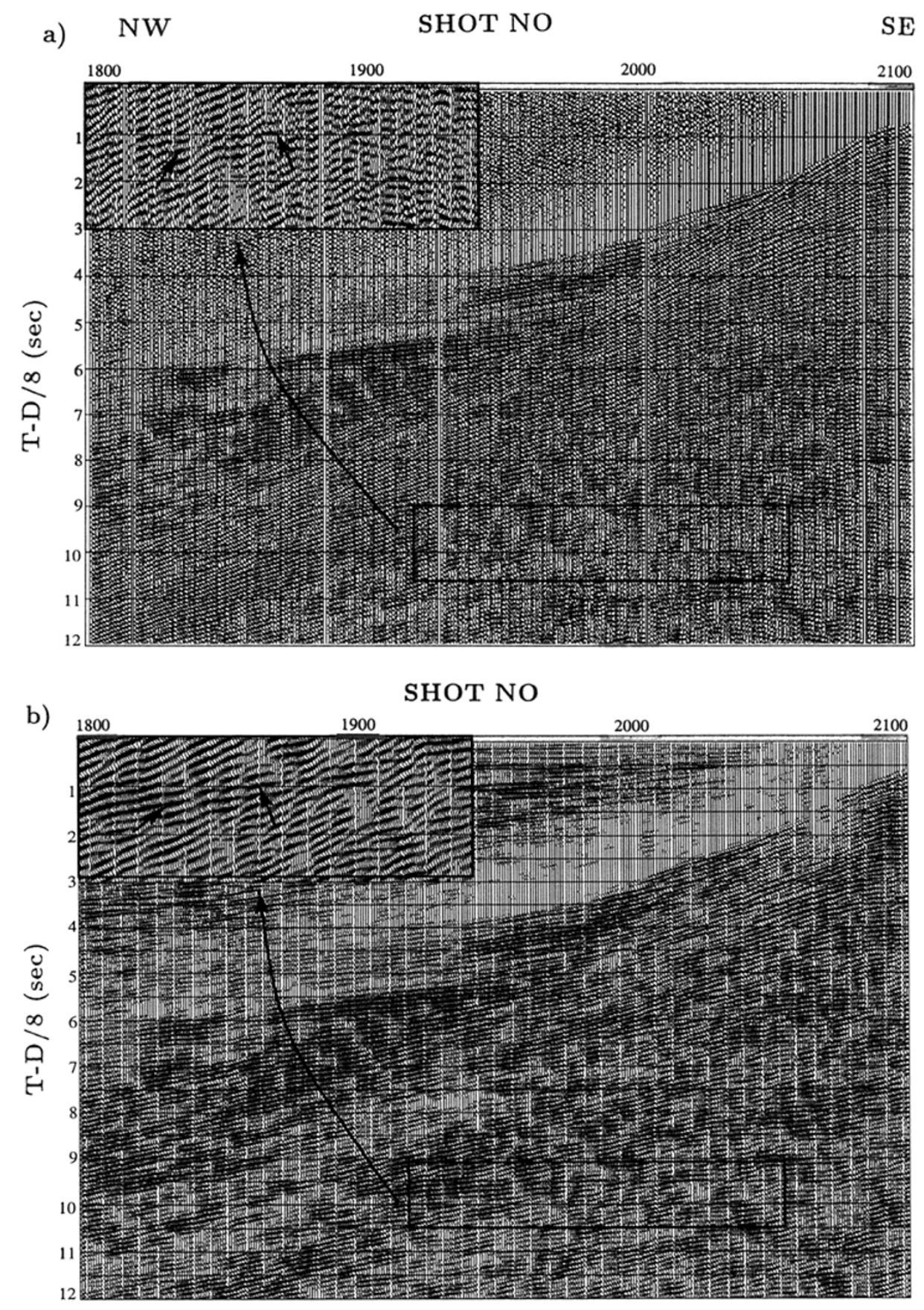

Fig. 12. (a) Horizontal high-gain component (channel 1) of OBS 1, high-frequency data. Plotted with $4 \mathrm{~s} \mathrm{AGC,} 8.0 \mathrm{~km} / \mathrm{s}$ reduction velocity, and 5-14 $\mathrm{Hz}$ band-pass filter. (b) Same as (a), but after application of radon filtering. Notice the appearance of a deep high-velocity arrival, barely interpretable before filtering.

ysis of our data. Two intermediate depth PPS arrivals are indicated on the in-line component in Fig. 13(a). These arrivals propagate with apparent $\mathrm{P}$-wave velocities, and represent waves that have been P-to-S converted on the way up (Mjelde et al., 2002). Figure 13(b) shows how the two arrivals, labelled A and B, are shifted in time between the in-line and cross-line components, suggesting that they represent arrivals that have propagated with different velocities on the way up. This is confirmed by studying the hodograms (Fig. 14), which demonstrates that the two first arrivals are polarized at $10-30^{\circ}$ angle from the in-line direction, whereas the second arrivals are polarized at ca. $70^{\circ}$ angle from the first arrivals. This could be interpreted in terms of fluid-filled microcracks aligned vertically, striking $10-30^{\circ} \mathrm{SW}$ of the azimuth of the profile.

It is generally possible to estimate the amount of anisotropy from the delay between the observed arrivals. These estimates are uncertain in our case, however, since it is difficult to pick up clear onsets of the second arrivals. The hodograms manifest interference between the two S-waves and indicate gradual change between the dominant polarization directions (Fig. 14). Furthermore, detailed ray-tracing is needed to identify the path of propagation for the different arrivals, before such estimates can be made more accurately. 

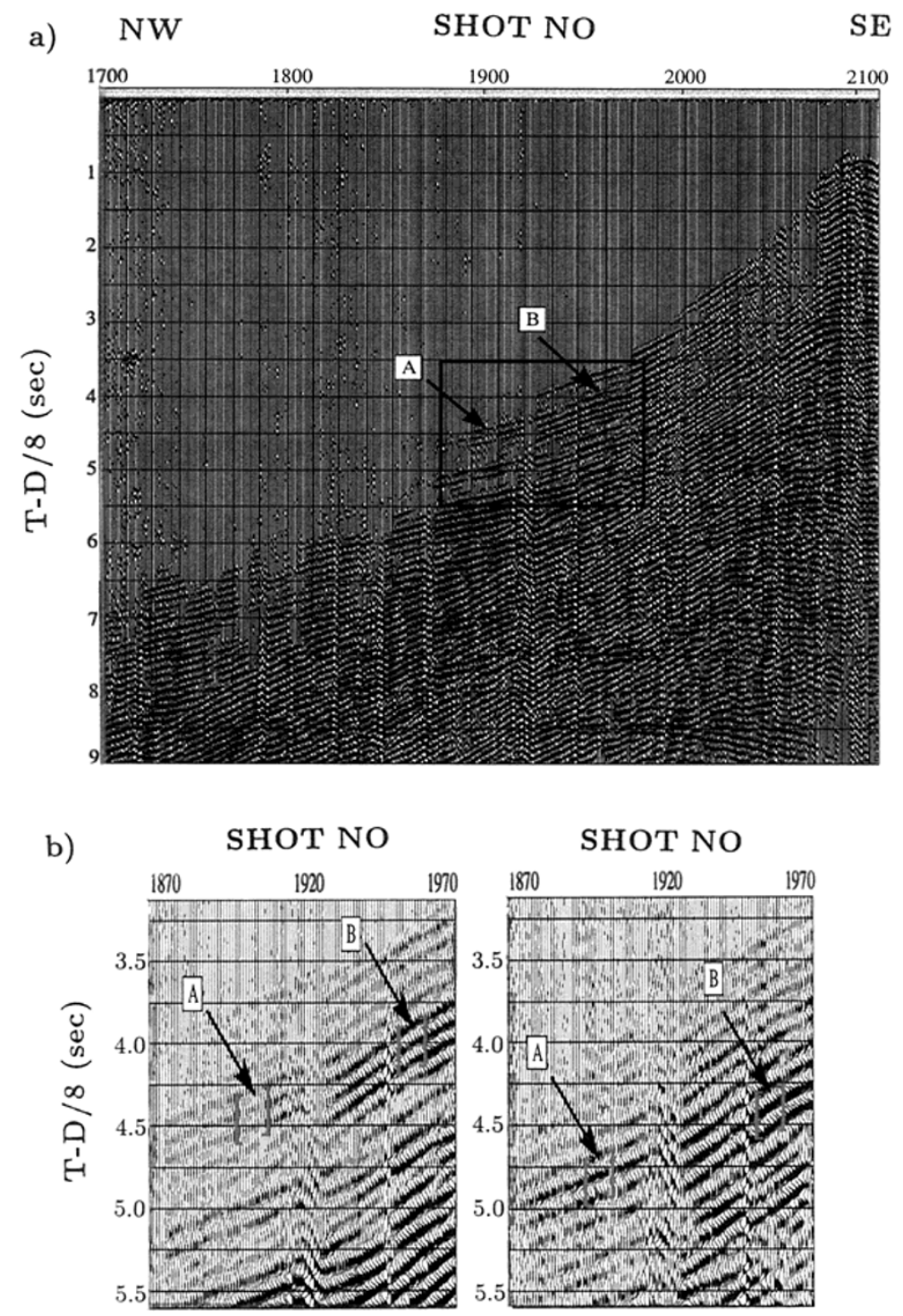

Fig. 13. (a) In-line horizontal high-gain component of OBS 1, high-frequency data. Plotted with $4 \mathrm{~s} \mathrm{AGC,} 8.0 \mathrm{~km} / \mathrm{s}$ reduction velocity, 5-14 Hz band-pass filter, and FK filter (arrivals with apparent velocities below $2 \mathrm{~km} / \mathrm{s}$ removed). Arrivals A and B have been studied with hodograms. (b) Left: Blow-up of portion of (a). Right: Same blow-up (and processing) of the cross-line component. Note the delay of arrivals compared with the in-line plot.

In our case, a rough identification of phases can be done by comparisons with the modeling of the low-frequency data (Digranes et al., 1996). Comparisons between estimates of splitting and propagation depths indicates that the splitting increases with propagation depth, from ca. $200 \mathrm{~ms}$ for intermediate sedimentary arrivals to a maximum of ca. 500 ms for crystaline crustal arrivals. This could be interpreted as vertical microcracks extending throughout the sedimentary section. The average anisotropy in the entire sedimentary section would, based on these phase identifications, be in the order of $7 \%$. These observations confirm the results of Digranes et al. (1996), who estimated NW-SE alignment of microcracks extending down to deep sedimentary levels, as well as in the lower crust, based on azimuthal anisotropy modelled from crossing profiles. These authors did not constrain their results by use of particle diagrams. The amount of anisotropy was estimated by Digranes et al. (1996) to be $5 \%$. The direction of fast direction corresponds to other measurements of the present-day stress-field in the area, pointing at slight compression from the mid-Atlantic spreading ridge as its main regional cause (Bungum et al., 1990).

The crustal structure immediately to the southwest and northeast of the study area has been mapped by Mjelde et al. (1997a) and Mjelde et al. (1998), respectively. Their results indicate that there are no major structures located near the studied profile that would cause significant offline reflections. It can thus be concluded that the observed pattern of Swave interference is most likely indicative of anisotropy, not crustal heterogeneities. However, it must be emphasized that the fact that high resolution OBS-data have been acquired along one profile only, implies that more detailed modeling of the data is needed to constrain the results.

\section{Discussion}

As described in Section 3, the low-frequency data could be effectively modeled by use of ray-tracing (Mjelde et al., 1997b). The high-frequency data appear to contain more details than the low-frequency data, and all parts of the datasets 
a)

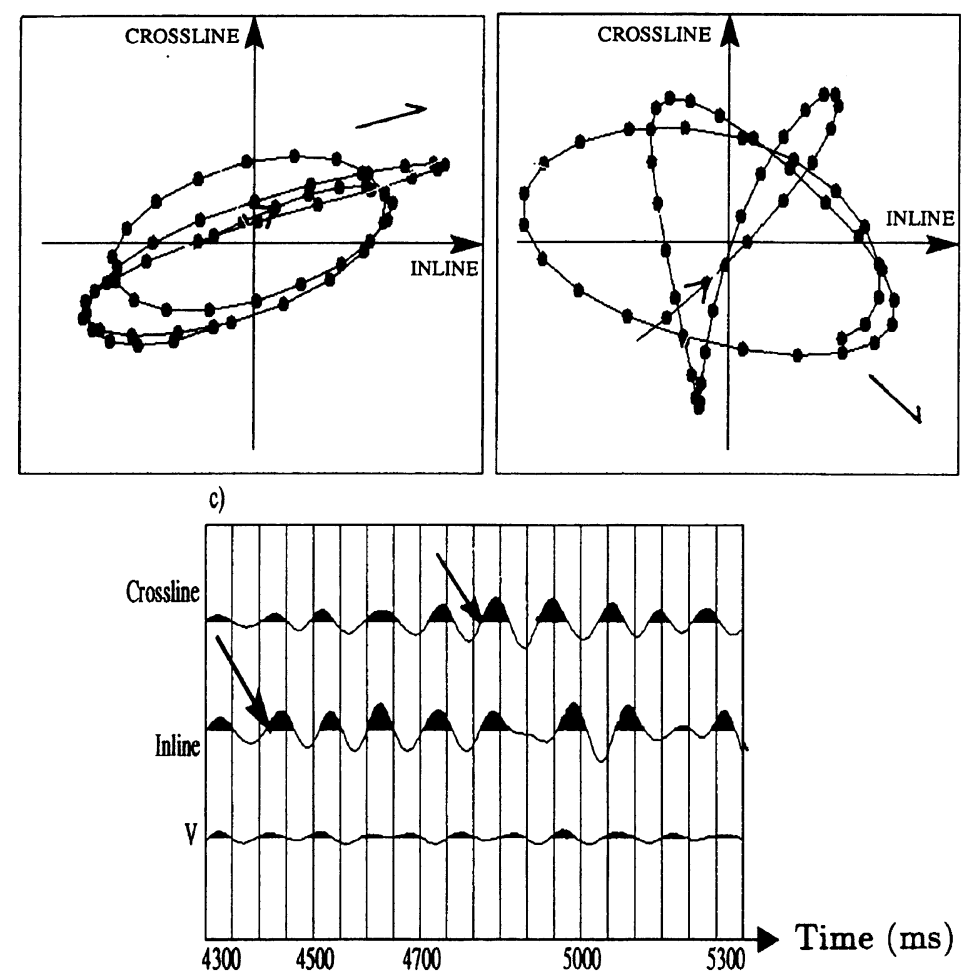

b)
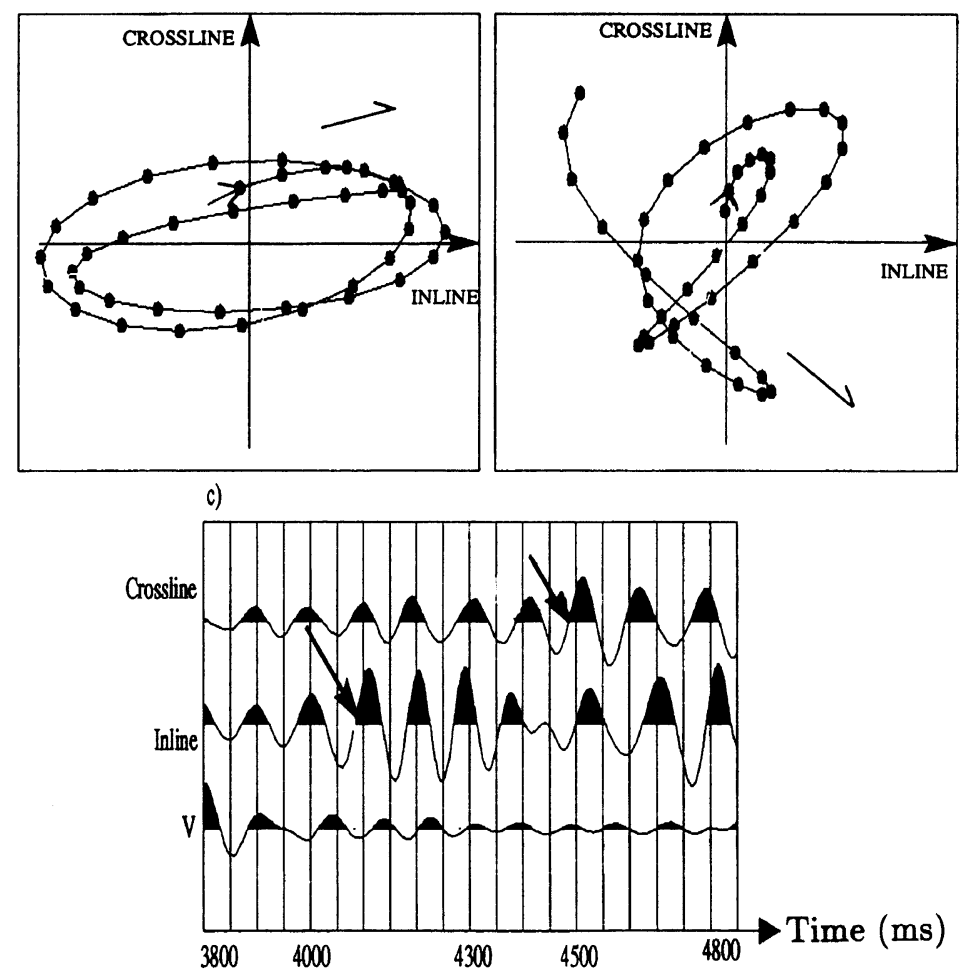

Fig. 14. (a) Hodogram of arrival A in Fig. 13. Left: 4400-4700 ms time-window, showing the polarization of the fast arrival close to the in-line direction. Right: $4700-5000 \mathrm{~ms}$ time-window, showing how the polarization changes gradually to that of the slow arrival, ca. $70^{\circ}$ from the fast arrival. Below: Interpretation of onset of fast and slow arrivals. (b) Same as (a), but for arrival B, and time-windows 4085-4385 ms and 4385-4685 ms, respectively.

have been compared visually to evaluate whether ray-tracing based on the high-frequency data might be expected to improve the semi-local model (Fig. 4(b)) significantly. This analysis has been done by testing various applications of the different processing schemes described in Section 5. This procedure is necessary, since the best plot is not the one where all processing routines have been applied at the same time; the best processing scheme must be designed accord- 

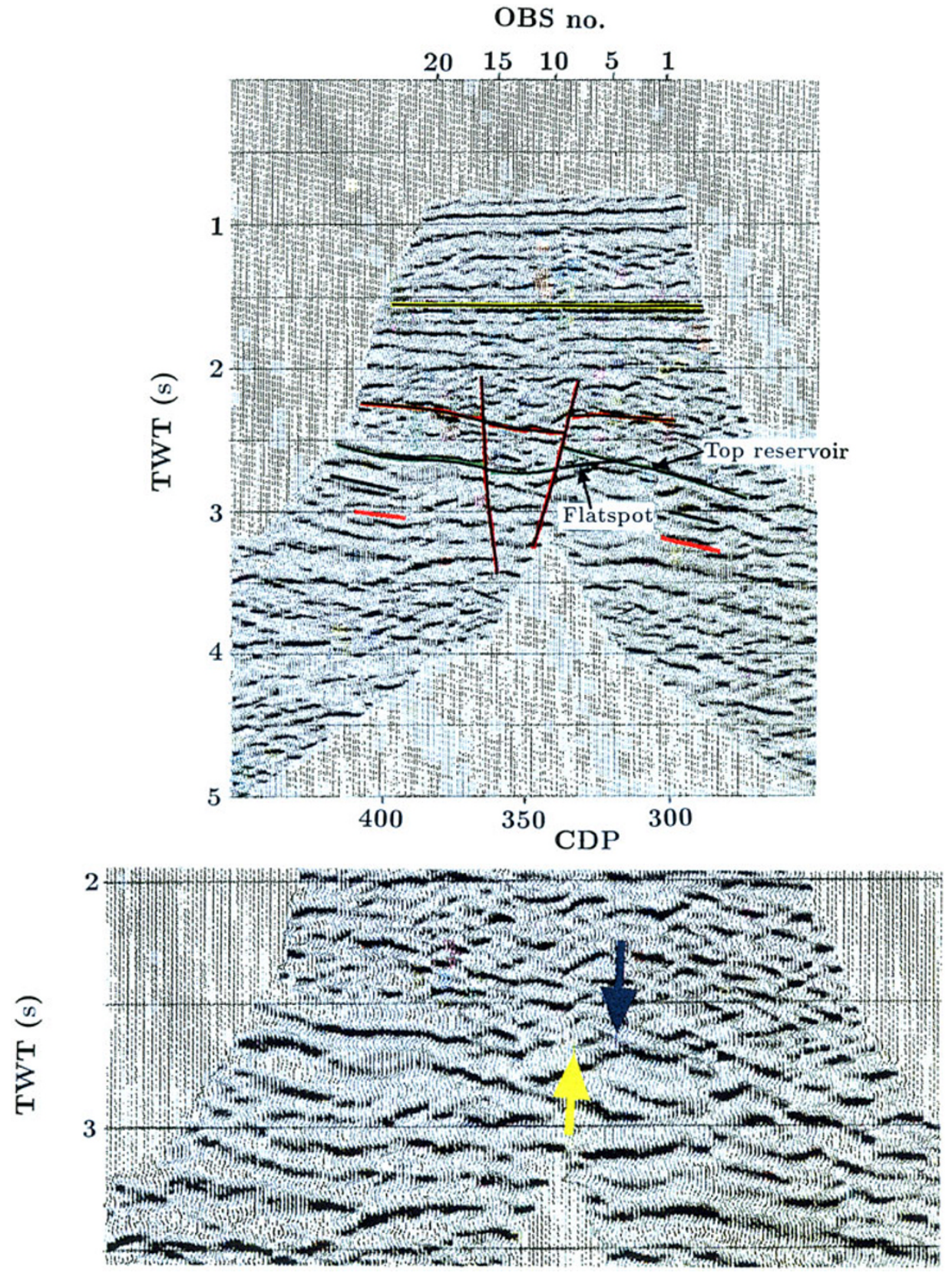

Fig. 15. Interpreted vertical component stack, high-frequency, local data. The arrows on the enlarged part indicate the top and base of the studied hydrocarbon reservoir, respectively (from Berg et al., 2001).

ing to which arrivals one aims to enhance.

To facilitate the description, each OBS is devided in two sections; to the NW and to the SE. An inspection of all the processed high-frequency data reveals that data from six OBSs (OBS 1, 12, 20, 21, 22 and 24) do not seem to contain any significant additional information compared to the corresponding low-frequency data. The remaining OBSs contain arrivals in the high-frequency data that might contain significant additional information either to the NW or to the SW, but for twenty-two of the sections the high-frequency data do not appear to contain significant new information. The remaining sixteen sections contain arrivals that might represent a potential local improvement of the semi-local model. The high-frequency data do not, however, reveal any new important arrivals that can be correlated from OBS to OBS. From the inspection of the data we can thus conclude that relatively time-consuming ray-tracing modeling of the high-frequency data would only result in minor and localized improvements of the semi-local model.

The modeling of the low-frequency semi-local data showed that the closer OBS-spacing, as compared to the regional study, resulted in significant additional information in all parts of the model. It was emhasized, however, that the over-all appearence of the regional and semi-local models seemed remarkably similar, and we suggest that this can be partly explained by the fact that anisotropy has been disregarded in the modeling. It is thus suggested that further detailed modeling of the data, if performed, should include anisotropic ray-tracing. Such ray-tracing, which falls beyond the scope of this paper, would also be needed to better quan- 
tify the observed S-wave anisotropy, and to determine its distribution with depth.

\section{Recommendations on Acquisition Parameters}

The modeling of the semi-local, high-frequency data presented in this paper completes the analysis of the various datasets acquired during the 1992 OBS-survey in the Vøring Basin. As we expect that many of the results may be of relevance to planned surveys along other continental margins, we will here summarize the main results on acquisition parameters.

- In regional surveys where mapping of lower crustal and upper mantle structures are considered important, the recommended shot- and receiver spacing is ca. $200 \mathrm{~m}$ and 15-30 km, respectively. Shorter receiver spacing will reduce the number of regional profiles that can be acquired within a given timeframe. The source may be non-tuned, but it is important that it generates a significant amount of frequencies as low as $6 \mathrm{~Hz}$.

- In semi-local surveys, where the main aim is mapping of the sedimentary and upper crystaline section (down to ca. 15 depth), the recommended shot- and receiver spacing is ca. $50 \mathrm{~m}$ and ca. $5 \mathrm{~km}$, respectively. The source should be tuned, and its frequency spectrum should be reasonably flat within the $10-40 \mathrm{~Hz}$ range. The denser shot spacing will allow more sophisticated processing, e.g. FK filtering to be made.

- If conventional multichannel processing is to be successful, the receiver spacing should idealy be ca. $200 \mathrm{~m}$ and it should not exceed $2 \mathrm{~km}$. The source parameters may be the same as for semi-local surveys.

- In local surveys, where the main focus is mapping of e.g. a hydrocarbon reservoir, the receiver spacing should be in the 50-200 m range. The frequency content of the source will depend on the depth of the target, but frequencies above $40 \mathrm{~Hz}$ will generally be needed. The data quality of such surveys may be improved by replacing traditional OBSs by $4 \mathrm{C}$ sensors incorporated in cables (Mjelde et al., 2002).

\section{Conclusions}

The vertical and horizontal components of semi-local OBS-data shot with a high-frequency source in the Vøring Basin, mid-Norwegian Margin, NE Atlantic, have been processed and compared to a dataset acquired by use of a lowfrequency source.

Spectral analysis of the noise demonstrates that the noise can be classified into three different groups; noise caused by water currents, instrumental noise and cultural noise. The noise from water currents is manifested in the $0-3 \mathrm{~Hz}$ frequency-band, whereas the instrumental noise is present in the $50-70 \mathrm{~Hz}$ frequency-range. These two components of noise can be effectively removed by use of band-pass filtering. Cultural noise within the seismic band-width $(5-40 \mathrm{~Hz})$ is to a certain degree present along most of the profile.

The decay of the amplitudes of the signal has been studied as function of offset for the three dominant frequency-peaks of the signal; 6,10 and $18 \mathrm{~Hz}$. It is revealed that an important difference between the two sources used is that the lowfrequency source generates significantly more energy around $6 \mathrm{~Hz}$. This higher content of very low frequencies allows detection of arrivals to larger offsets, since the attenuation of the higher frequencies (10 Hz and higher) is strong for deep crustal and upper mantle arrivals. Although the shot-spacing is about 4 times larger for the low-frequency data, arrivals can generally be observed to larger offset in these data; to 59 $\mathrm{km}$ (mean maximum offset for all OBSs), compared to 53 $\mathrm{km}$ for the high-frequency data.

In order to investigate how the differences in the sources qualitatively affect the seismic data, the high-frequency data has been plotted using every 4th trace only. For the nearest offsets (reflections and refractions from the shallow to intermediate sedimentary levels) the high-frequency source is clearly able to resolve some more details than the lowfrequency source. This is mainly caused by the fact that the high-frequency source has a much sharper primary pulse and reduced bubble pulse compared to the low-frequency source. In addition, a slightly increased level of higher frequencies also contributes to the differences in resolution. Plotting every 4th trace of the high-frequency data causes as expected a decrease in the maximum offset of clearly identifiable arrivals, compared to the complete seismic section. Decreasing the spacing between the shots thus clearly increases the useful penetration depth of the survey. The differences in the content of lower frequencies for the two sources are so important, however, that the penetration depth is significantly larger for the low-frequency acquisition.

Weighted trace mixing enhances the continuity of the faroffset arrivals for both datasets. Trace mixing thus increases the quality of the data, although the data enhancement is generally restricted to increasing the continuity of arrivals that can be weakly observed without such processing.

The water-arrival and shallow sedimentary refractions $(1470-2400 \mathrm{~m} / \mathrm{s}$ ) have been effectively removed from the high-frequency data by use of FK (velocity) filtering. This filtering clearly enhances the interpretation of the near-offset arrivals. The same filtering cannot be applied to the lowfrequency data due to spatial aliasing. The high velocity arrivals (above $5500 \mathrm{~m} / \mathrm{s}$ ) can be effectively removed from both datasets. This filtering enhances the interpretation of secondary arrivals propagating with apparent velocities of about $3000 \mathrm{~m} / \mathrm{s}$. Application of Radon transform filtering has the same advantages.

Minimum phase prediction deconvolution removes ringing from the data, and the onset of the different arrivals can be interpreted with larger certainty. This is true for both datasets, although the effect is larger for the high-frequency data.

Visual comparison of the two datasets shows that some arrivals are easier to interpret in the high-frequency than in the low-frequency data. However, the shot-spacing of the low-frequency data is generally short enough to allow accurate detection of arrivals observed in the high-frequency data. The high-frequency data do not reveal any new important arrivals that can be correlated from OBS to OBS. It is thus concluded that systematic ray-tracing modeling of the high-frequency data would only result in minor and localized 
improvements of the semi-local model.

Due to the higher content of low frequencies (below 10 $\mathrm{Hz}$ ) in the low-frequency source, it can be concluded that this source should be employed in future regional studies ( $\geq 10 \mathrm{~km}$ between OBSs). A source of the high-frequency type should be used, however, in detailed studies of shallow targets (above ca. $5 \mathrm{~km}$ depth).

Inspection of particle diagrams (hodograms) reveals ca. 7\% S-wave anisotropy, interpreted to being caused by vertical microcracks in the sedimentary section aligned NW-SE by the present day maximum compressive stress-field.

Acknowledgments. Prof. M.A. Sellevoll, IFJ, is thanked for enthusiastic support throughout the initiation and planning of the experiment, and encouragements during the analysis of the data. We also thank the Norwegian Petroleum Directorate for giving the permission for the experiment, and Statoil for funding the experiment and for indispensable assistance during all stages of the work. In particular we thank E. W. Berg, O. Riise and A. Strøm.

\section{References}

Berg, E. W., L. Amundsen, A. Morton, R. Mjelde, H. Shimamura, H. Shiobara, T. Kanazawa, S. Kodaira, and J. P. Fjellanger, Three component OBS-data processing for lithology and fluid prediction in the midNorway margin, NE Atlantic, Earth Planets Space, 53, 75-89, 2001.

Bungum, H., A. Alsaker, L. B. Kvamme, and R. A. Hansen, Seismicity and seismotectonics of Norway and nearby continental shelf areas, $J$. Geophys. Res., 96(B2), 2,249-2,265, 1990.

Crampin, S., The scattering of S waves in the crust, Pure and Applied Geophysics, 132, 67-91, 1990.

Digranes, P., R. Mjelde, S. Kodaira, H. Shimamura, T. Kanazawa, H. Shiobara, and E. W. Berg, Modelling of shear waves in OBS data from the Vøring Basin (Northern Norway) by 2-D ray-tracing, Pure and Applied Geophysics, 4, 611-629, 1996.

Eldholm, O. and K. Grue, North Atlantic volcanic margins: Dimensions and production rates, J. Geophys. Res., 99, 2,955-2,968, 1994.

Kanazawa, T., Technical Description of TK92-type ocean bottom seismometer, in Investigation of the Central and Northern Part of the Vøring Basin by Use of Ocean Bottom Seismographs, R/V Håkon Mosby 22 Aug.-24 Sept. 1992, cruise report, Statoil report, Mjelde, R. et al., 1993.

Mjelde, R., M. A. Sellevoll, H. Shimamura, T. Iwasaki, and T. Kanazawa, A crustal study off Lofoten, N. Norway by use of 3-C ocean bottom seismographs, Tectonophys., 212, 269-288, 1992.

Mjelde, R., M. A. Sellevoll, H. Shimamura, T. Iwasaki, and T. Kanazawa, Crustal structure under Lofoten, N. Norway, from vertical incidence and wide-angle data, Geophys. J. Int., 114, 116-126, 1993.

Mjelde, R., M. A. Sellevoll, H. Shimamura, T. Iwasaki, and T. Kanazawa, S-wave anisotropy off Lofoten, Norway, indicative of fluids in the lower crust?, Geophys. J. Int., 120, 87-96, 1995.

Mjelde, R., S. Kodaira, H. Shimamura, T. Kanazawa, H. Shiobara, E. W. Berg, and O. Riise, Crustal structure of the central part of the Vøring basin, mid-Norway margin, from three-component ocean bottom seismographs, Tectonophys., 277, 235-257, 1997a

Mjelde, R., S. Kodaira, P. Digranes, H. Shimamura, T. Kanazawa, H. Shiobara, and E. W. Berg, Comparison between a regional and semiregional crustal OBS-model in the Vøring basin, mid-Norway margin, Pure and Applied Geophysics, 149, 641-665, $1997 \mathrm{~b}$.

Mjelde, R., J. P. Fjellanger, P. Digranes, S. Kodaira, H. Shimamura, and H. Shiobara, Application of the single bubble air-gun technique for OBS data acquisition across the Jan Mayen Ridge, North Atlantic, Marine Geophysical Researches, 19, 81-96, 1997c.

Mjelde, R., P. Digranes, H. Shimamura, H. Shiobara, S. Kodaira, H. Brekke, T. Egebjerg, N. Sørenes, and T. Thorbjørnsen, Crustal structure of the northern part of the Vøring Basin, mid-Norway margin, from wide-angle seismic and gravity data, Tectonophys., 293, 175-205, 1998.

Mjelde, R., J. P. Fjellanger, T. Raum, P. Digranes, S. Kodaira, A. Breivik, and H. Shimamura, Where do P-S converions occur? Analysis of OBSdata from the NE Atlantic Margin, First Break, 20, 153-160, 2002.

Neidell, N. S., Land application of S waves, Geophysics: The Leading Edge of Exploration, 11, 32-44, 1985.

Pajchel, J., H. B. Helle, and L. Frøyland, A 2-D seismic Modelling Package, User's Manual, Geophys. Dep., Norsk Hydro Research Center, Bergen, 1989.

Samson, C., P. J. Barton, and J. Karwatowski, Imaging beneath an basaltic layer using densely sampled wide-angle OBS data, Geophysical Prospecting, 43, 509-528, 1995.

Sellevoll, M. A., H. Shimamura, A. Gidskehaug, and H. Johnsen, Seismiske undersøkelser av Lofoten marginen og refleksjonsseismiske test-målinger på Mohns Rygg, M/S Håkon Mosby, 29. juli-19. august 1988, Cruise report, IFJ, Univ. of Bergen, 1988.

Shiobara, H., A. Nakanishi, H. Shimamura, R. Mjelde, T. Kanazawa, and E. W. Berg, Precise positioning of Ocean Bottom Seismometer by Using Acoustic Transponder and CTD, Marine Geophysical Researches, 19 199-209, 1997.

Trevorrow, M. V., T. Yamamoto, A. Turget, D. Goodman, and M. Badiey, Very low frequency ocean bottom ambient seismic noise and coupling on the shallow continental shelf, Marine Geophys. Res., 11, 129-152, 1989.

Webb, S. C. and C. S. Cox, Observations and modeling of seafloor microseisms, J. Geophys. Res., 91, 7343-7358, 1986.

R. Mjelde (e-mail: rolf.mjelde@ifjf.uib.no), T. Timenes, H. Shimamura, T. Kanazawa, H. Shiobara, S. Kodaira, and A. Nakanishi 